\title{
Recurrent and second primary squamous cell carcinoma of the head and neck: When and how to reirradiate
}

\begin{abstract}
Primož Strojan, MD, PhD, ${ }^{1}$ June Corry, MD, ${ }^{2}$ Avraham Eisbruch, $\mathrm{MD},{ }^{3}$ Jan B. Vermorken, MD, PhD, ${ }^{4}$ William M. Mendenhall, MD, ${ }^{5}$ Anne W. M. Lee, MD, FRCR, FHKCR, FHKAM, ${ }^{6}$ Missak Haigentz Jr, MD, ${ }^{7}$ Jonathan J. Beitler, MD, ${ }^{8}$ Remco de Bree, MD, PhD, ${ }^{9}$ Robert P. Takes, MD, PhD, ${ }^{10}$ Vinidh Paleri, MS, FRCS (ORL-HNS), ${ }^{11}$ Charles G. Kelly, MB, ChB, MSc, FRCP, FRCR, ${ }^{12}$ Eric M. Genden, MD, ${ }^{13}$ Carol R. Bradford, MD, ${ }^{14}$ Louis B. Harrison, MD, ${ }^{15}$ Alessandra Rinaldo, MD, FRCSEd ad hominem, FRCS (Eng, Ir) ad eundem, FRCSGlasg, ${ }^{16}$ Alfio Ferlito, MD, DLO, DPath, FRCSEd ad hominem, FRCS (Eng, Glasg, Ir) ad eundem, FDSRCS ad eundem, FHKCORL, FRCPath, FASCP, IFCAP16*

${ }^{1}$ Department of Radiation Oncology, Institute of Oncology, Ljubljana, Slovenia, ${ }^{2}$ Division of Radiation Oncology, Peter MacCallum Cancer Centre, Melbourne, Victoria, Australia, ${ }^{3}$ Department of Radiation Oncology, University of Michigan, Ann Arbor, Michigan, ${ }^{4}$ Department of Medical Oncology, Antwerp University Hospital, Edegem, Belgium, ${ }^{5}$ Department of Radiation Oncology, University of Florida, Gainesville, Florida, ${ }^{6}$ Center of Clinical Oncology, University of Hong Kong - Shenzhen Hospital, Shenzhen, China, ${ }^{7}$ Department of Medicine, Division of Oncology, Albert Einstein College of Medicine, Montefiore Medical Center, Bronx, New York, ${ }^{8}$ Departments of Radiation Oncology, Otolaryngology and Medical Oncology, Emory University School of Medicine, Atlanta, Georgia, ${ }^{9}$ Department of Otolaryngology-Head and Neck Surgery, VU University Medical Center, Amsterdam, The Netherlands, ${ }^{10}$ Department of Otolaryngology-Head and Neck Surgery, Radboud University Medical Center, Nijmegen, The Netherlands, ${ }^{11}$ Department of Otolaryngology-Head and Neck Surgery, Newcastle upon Tyne Hospitals, Newcastle upon Tyne, United Kingdom, ${ }^{12}$ Department of Clinical Oncology, Northern Centre for Cancer Care, Freeman Hospital, Newcastle upon Tyne, United Kingdom, ${ }^{13}$ Department of Otolaryngology-Head and Neck Surgery, The Mount Sinai Medical Center, New York, New York, ${ }^{14}$ Department of Otolaryngology-Head and Neck Surgery, University of Michigan, Ann Arbor, Michigan, ${ }^{15}$ Department of Radiation Oncology, Beth Israel Medical Center and St. Luke's-Roosevelt Hospitals, New York, New York, ${ }^{16}$ ENT Clinic, University of Udine, Udine, Italy.
\end{abstract}

ABSTRACT: Background. Local and/or regional recurrence and metachronous primary tumor arising in a previously irradiated area are rather frequent events in patients with head and neck squamous cell carcinoma (HNSCC). Re-treatment is associated with an increased risk of serious toxicity and impaired quality of life (QOL) with an uncertain survival advantage.

Methods. We analyzed the literature on the efficacy and toxicity of photon/electron-based external beam reirradiation for previously irradiated patients with HNSCC of non-nasopharyngeal origin. Studies were grouped according to the radiotherapy technique used for reirradiation. Patient selection criteria, target volume identification method, tumor dose, fractionation schedule, systemic therapy administration, and toxicities were reviewed.

Results. In addition to disease-related factors, current comorbidities and preexisting organ dysfunction must be considered when selecting patients for reirradiation. As morbidity from re-treatment may be considerable and differ depending on which mode of re-treatment is used, it is important to give patients information on potential morbidity outcomes so that an informed choice can be made within a shared decisionmaking context. With improved dose distribution and adequate imaging support, including positron emission tomography-CT, modern radiother- apy techniques may improve local control and reduce toxicity of reirradiation. A reirradiation dose of $\geq 60$ Gy and a volume encompassing the gross tumor with up to a 5-mm margin are recommended. Concomitant administration of systemic therapeutics and reirradiation is likely to be of similar benefit as observed in large randomized studies of upfront therapy.

Conclusion. Reirradiation, administered either with or without concurrent systemic therapy, is feasible and tolerable in properly selected patients with recurrent or a new primary tumor in a previously irradiated area of the head and neck, offering a meaningful survival (in the range of $10 \%$ to $30 \%$ at 2 years). Whenever feasible, salvage surgery is the method of choice for curative intent; patients at high-risk for local recurrence should be advised that postoperative reirradiation is expected to increase locoregional control at the expense of higher toxicity and without survival advantage compared to salvage surgery without reirradiation. (c) 2014 Wiley Periodicals, Inc. Head Neck 37: 134-150, 2015

KEY WORDS: head and neck cancer, squamous cell carcinoma, recurrence, second primary cancer, reirradiation, salvage surgery, systemic therapy

\section{INTRODUCTION}

Initial multimodality treatments for locally advanced head and neck squamous cell carcinoma (HNSCC) can

${ }^{*}$ Corresponding author: A. Ferlito, ENT Clinic, University of Udine, Piazzale S. Maria della Misericordia, I-33100 Udine, Italy. E-mail: a.ferlito@uniud.it

This paper was written by members and invitees of the International Head and Neck Scientific Group. be unsuccessful, resulting in persistent or recurrent disease, and the past and current lifestyle choices of many patients increase their risk for new primary cancers even if the initial tumor was cured. Recurrent and second primary HNSCC in previously radiated regions pose a unique challenge to clinicians dealing with this disease. As multidisciplinary management is common in head and neck oncology, most of these patients already have received considerable intensified prior 
treatment consisting of surgery, radiotherapy (RT), and/ or chemotherapy.

In the present study, we reviewed the efficacy and toxicity of photon/electron-based external beam reirradiation as salvage treatment of HNSCC for patients previously irradiated for HNSCC primary tumors of nonnasopharyngeal origin. Reports using brachytherapy as the main reirradiation procedure were not included in the present analysis. ${ }^{1}$

\section{MATERIALS AND METHODS}

A systematic review of the English-language literature was conducted using the PubMed database with the following search terms: reirradiation, re-treatment, and head and neck cancer. The content of publications identified in the search results was reviewed for possible inclusion, and references were checked for additional relevant reports. Only studies fulfilling the following criteria were included: (1) published as a full article in peer-reviewed journals; (2) the majority of patients had nonnasopharyngeal primaries and the prevailing histology was squamous cell carcinoma; (3) results for different RT techniques were reported separately; and (4) overall survival (OS) data was reported or could be estimated from the Kaplan-Meier plot.

Depending on the RT technique used in a particular study, salvage treatments were divided into 4 groups: (1) salvage surgery performed with curative intent in combination with reirradiation using conventional techniques; (2) reirradiation for unresectable disease using conventional techniques; (3) reirradiation using intensity modulated radiotherapy (IMRT); and (4) reirradiation using stereotactic body radiotherapy (SBRT). In addition, the quantitative aspect and other issues specifically related to reirradiation (target volume definition, tumor dose, regimen, and tolerance of reirradiated tissues) were reviewed and discussed together with systemic drugs used in conjunction with reirradiation and criteria for the selection of patients who are likely to benefit from aggressive reirradiation programs.

\section{RESULTS}

\section{Extent of the problem}

By definition, HNSCC is largely a locoregional problem, with the distribution of most recurrences after primary, curative-intent RT regimens occurring within the treatment field. According to the Meta-Analysis of Chemotherapy in Head and Neck Cancer (MACH-NC) data from 50 concomitant chemotherapy-RT trials and 30 induction chemotherapy trials, the rates of local and/or regional recurrence at 5 years were $50.8 \%$ and $47.5 \%$ in the experimental arms, respectively, and $60.1 \%$ and $46.5 \%$ in the control arms (ie, RT alone) of the trials, respectively. ${ }^{2}$ The corresponding rates of distant metastasis were below 20\%. Although patients with locoregional tumor recurrence can be considered salvageable with surgical and/or reirradiation-based therapies, considering the health status and preferences of patients with recurrence, morbidity after previous therapies and the extent of the disease, approximately half or less were amenable to sal- vage surgery or other curative intent treatment strategies. $^{3-6}$

Another indication for re-treatment in a previously irradiated area of the head and neck is metachronous HNSCCs. Their appearance relates to a lengthy exposure of the upper aerodigestive tract mucosa to the immoderate use of tobacco and alcohol, resulting in a "field cancerization" effect, and genetic predisposition. ${ }^{7,8}$ Analyzing the Radiation Therapy Oncology Group (RTOG) registry with 2066 patients prospectively entered with HNSCC, Cooper et al $^{9}$ identified 601 patients without prior/coincident of another malignant tumor who were treated with RT alone and were free of disease at 6 months postherapy. The estimated risk of developing a second malignant tumor in these patients at 3, 5, and 8 years (plus 6 months) from the start of RT was 9\%, 14\%, and 23\%, respectively, and the proportion of new primary tumors arising in the head and neck was $18 \%$. A study presenting the University of Florida experience on 1112 patients with HNSCC treated with curative RT and followed for at least 2 years was reported by Erkal et al. ${ }^{10}$ Among these patients, there were $9 \%$ who developed a new HNSCC at 0.6 to 21.7 years after RT, and the rates of occurrence of a second primary HNSCC at 5 years by the site of the initial malignancy were $11 \%, 12 \%$, and $3 \%$ for patients with carcinoma of the oropharynx, hypopharynx, and supraglottic larynx, respectively. In the series from the MD Anderson Cancer Center, 3.4\% of 1292 patients with HNSCC who completed different treatment programs developed a second HNSCC, corresponding to $36.7 \%$ of all second primary tumors diagnosed in this cohort. ${ }^{8}$

\section{Re-treatment strategies}

Patients who present with a locoregional recurrence or a second primary HNSCC are frequently heavily pretreated with surgery and RT, with or without chemotherapy, or both. Surgical salvage has proven to be the most effective curative-intent treatment and is the treatment of choice for all patients with resectable tumors and sufficiently good health status. According to a meta-analysis of 32 studies with a total of 1080 patients reported by Goodwin, ${ }^{11}$ a survival rate of $39 \%$ can be expected at 5 years after salvage surgery. The best chance for cure has been reported for patients with early-stage recurrent tumors, whereas those with rT3-classified and rT4classified recurrent disease should be considered poor candidates to undergo salvage surgery. ${ }^{3,11,12}$ The efficacy of salvage surgery also correlated with the site of recurrent cancer, and the outcome tended to be better in recurrent cancer of the larynx as compared to other tumor sites. However, the impact of the treated site was found to be less important than recurrence stage. ${ }^{11}$

The role of chemotherapy as a single therapeutic modality in such patients is palliative. A phase III clinical trial has shown that the median survival of patients with recurrent, unresectable HNSCC can be improved from 7.4 to 10.1 months (hazard ratio [HR], $0.80 ; p=.04$ ) with the addition of cetuximab to platinum/5-fluorouracil (FU) systemic therapy. ${ }^{13}$ However, it is known from earlier randomized trials in recurrent/metastatic HNSCC that, with platinum-based combination chemotherapy, only $3.6 \%$ of patients are still alive after 5 years. ${ }^{14}$ 
In recurrent, unresectable head and neck cancer, decision analysis models informed by results from systematic reviews and expert panel-generated utility values showed that concurrent chemotherapy and reirradiation offers an improvement in quality of life (QOL)-years of approximately 5 weeks compared to best supportive care. ${ }^{15}$

Reirradiation (using conventional techniques) and combinations with other treatment modalities: a review of effectiveness. In the era of conventional RT techniques, several retrospective reports, but only a few prospective studies, have been published using reirradiation as a salvage modality in locoregional recurrence and/or second primary HNSCC. There have been only 2 prospective phase III studies exploring the efficacy of conventional reirradiation, and one of them was underpowered because of slow accrual resulting in premature closure.

Reirradiation after salvage surgery. In 2008, the Groupe d'Etude des Tumeurs de la Tête Ed du Cou and Groupe d'Oncologie Radiothérapie Tête et Cou (GORTEC) groups reported on a phase III randomized trial of postoperative reirradiation combined with chemotherapy compared with salvage surgery alone. ${ }^{16}$ Between 1999 and 2005, a total of 130 patients from 16 French and Belgian centers were randomized to the trial arms. Surgical resection encompassed a lymph node dissection in $84 \%$ of patients, although two-thirds had cN0 disease. Histopathological examination of the resected specimens revealed positive/ close margins, extracapsular rupture, or $>1$ invaded nodes in $49 \%$ of the patients. In the experimental arm, patients were to receive 6 cycles of $5 \times 2$ Gy/fraction (fx) reirradiation, concomitantly with hydroxyurea/5FU, with a 9-day rest period between cycles. The tumor bed with a 1 - to 2-cm margin and the first adjacent metastasis-free nodal area were irradiated. Significant improvements in locoregional control (LRC; HR, 4.51; $p<.0001$ ) and disease-free survival (DFS; HR, 1.68; $p=.01$ ) were observed in the reirradiation arm, but OS (45\% at 2 years in the reirradiation arm) did not differ between the 2 arms because of more treatment-related deaths, distant metastases, and second primary tumors among the reirradiated patients. An increase in serious (grade 3 or 4) late toxicities was associated with adjuvant therapy $(39 \%$ vs $10 \%$ at 2 years; $p=.06$ ), and 5 treatment-related deaths were recorded in this group.

Several smaller prospective or retrospective series have been reported in the literature, and the main characteristics and results from these reports are presented in Table $1^{16-25}$ Conclusions drawn from these studies might include the following: (1) only patients with high-risk features found at histopathological examination of the resected specimen should be considered for postoperative reirradiation (eg, close or involved surgical margins and extracapsular tumor extension); (2) grade 3 or 4 late toxicities occur in greater than a third of the patients; (3) up to $8 \%$ of patients will die because of causes related to retreatment; (4) OS rates in the range of $40 \%$ to $50 \%$ at 2 years are achievable (in a selected population of fit patients with smaller tumor volumes than in those not amenable to salvage surgery); and (5) compared to salvage surgery alone, adjuvant reirradiation (with or without concomitant chemotherapy) improves LRC and DFS but has no effect on OS. It is not clear whether the addition of concurrent chemotherapy to reirradiation improves treatment efficacy.

The morbidity and mortality associated with adjuvant reirradiation cannot be understated. Some have suggested that the introduction of vascularized tissue in the form of a muscle flap may help to protect the vascular structures and the overlying skin from radiation injury. Suh et $\mathrm{al}^{24}$ retrospectively evaluated 12 patients who received microvascular free flap reconstruction for recurrent or second primary head and neck cancer in a previously irradiated field. All free flaps were inset directly into the field of previous radiation and were exposed to reirradiation. The authors compared their results with the published complication rate and they found that microvascular free flaps allow for maximal resection and reliable reconstruction of previously irradiated cancers before high-dose reirradiation and may reduce the incidence of severe late complications and treatment-related mortality. In those patients who are undergoing salvage surgery with the intent on reirradiation, the introduction of vascularized tissue may reduce the rate of skin sloughing, spontaneous fistula, and great vessel rupture.

Reirradiation for unresectable disease. The only trial with randomized design was conducted by the French Head and Neck Oncology Radiotherapy Group (GORTEC 9803 ) during 1999 to 2005 and was closed prematurely. ${ }^{26}$ Only 57 patients (of a planned 160 patients), unsuitable for any curative salvage therapy, were randomized between weekly single agent methotrexate (until disease progression or toxicity, 27 patients) or 6 cycles of reirradiation $(5 \times 2 \mathrm{~Gy} / \mathrm{fx} /$ cycle $)$ and concurrent hydroxyurea/5FU (30 patients), with a 9-day intercycle rest period. The irradiated volume encompassed the gross tumor volume (GTV) with $\geq 2-\mathrm{cm}$ margin and the first adjacent nodal station. With more rT3-4 tumors in the reirradiation arm (88\% vs 60\%), 4 patients from this group experienced a complete response (but none in the methotrexate arm), although no differences in OS was found between the 2 approaches (1-year survival, $22 \%$ vs $23 \% ; p=.6)$. The reirradiation arm proved to be more toxic compared to the methotrexate arm with regard to treatment-related deaths (3 vs 1) and grade 3/4 late toxicities (11 vs 5).

In 2004, the RTOG launched a phase III randomized trial (RTOG 04-21) comparing concomitant chemotherapy and reirradiation (the same regimen as in the RTOG 9911, see below) and 3 cisplatin-based standard chemotherapy regimens. As in the case of the GORTEC 98-03 trial, it was closed prematurely because of poor accrual, and results have not been reported.

However, the RTOG designed and successfully conducted 2 multi-institutional prospective phase II trials. In the RTOG 9610 trial (1996-1999), a total of 86 patients were recruited and treated with 4 weekly cycles of chemotherapy and reirradiation (1.5 Gy/fx b.i.d., concurrently with hydroxyurea/5FU, days 1-5), separated by 1 week of rest. ${ }^{27}$ Only the gross disease was irradiated with a margin of $\geq 2 \mathrm{~cm}$. Of 79 analyzable patients, all 4 chemotherapy cycles and $>54.6$ Gy were received by $73.4 \%$ and $77.2 \%$ patients, respectively. In the acute phase of the protocol, there were 6 treatment-related deaths $(7.6 \%)$; 


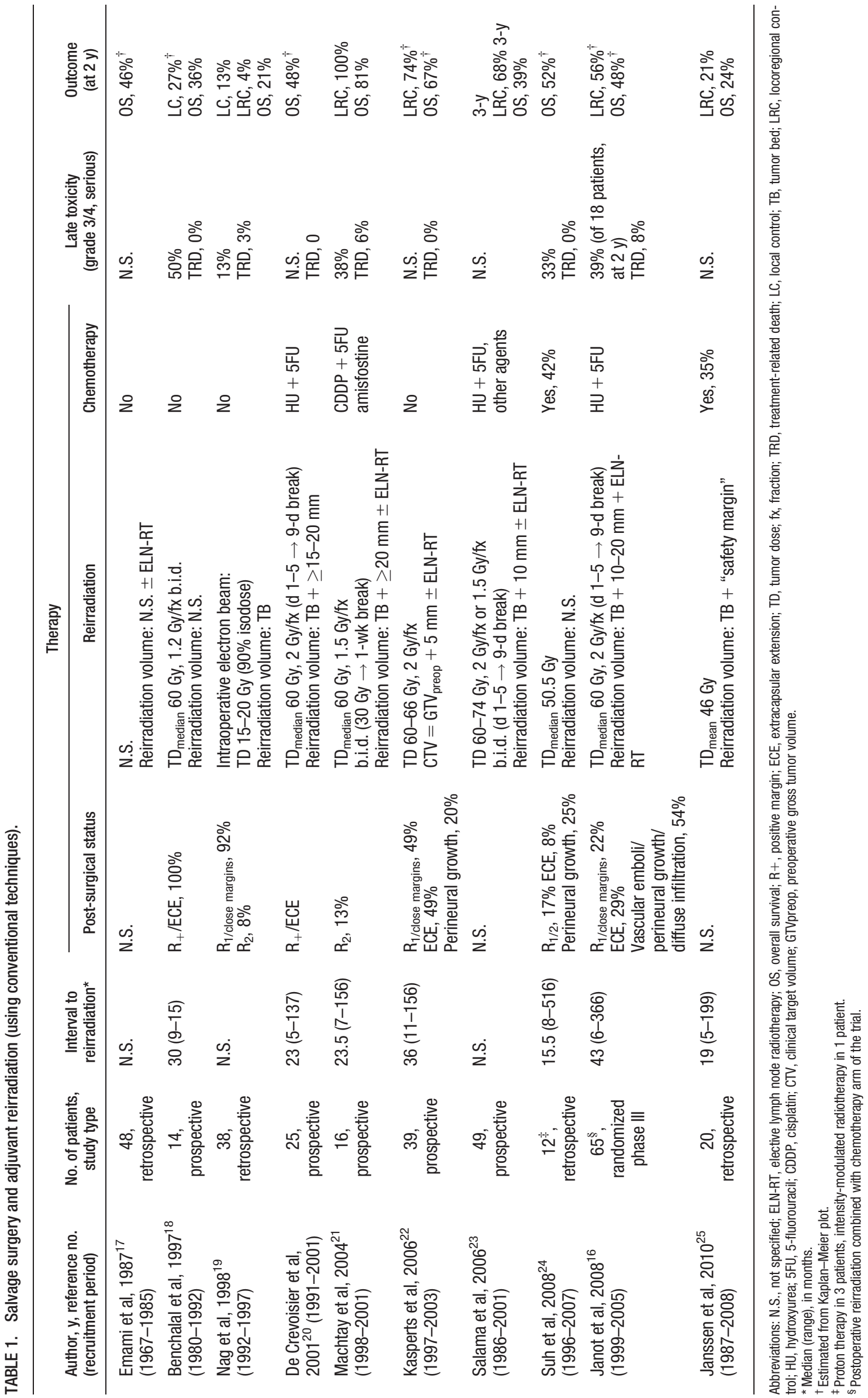


$69.6 \%$ of patients had a feeding tube at the last followup, and the estimated cumulative incidence of late grade $3 / 4$ toxicities at 2 and 5 years was 9.4\%. Death was related to the index cancer in $72.7 \%$ of the patients, and OS was $15.2 \%$ at 2 years. The second study (RTOG 9911) was conducted during 2000 to 2003 and included 105 patients who were treated according to the same reirradiation protocol (IMRT was allowed and used at the discretion of the investigator) but with a different chemotherapy regimen (cisplatin/paclitaxel, concurrently with reirradiation, days 1-5) and granulocyte colonystimulating factor support (days 6-13, every other week). ${ }^{28}$ All 4 chemotherapy cycles were completed in $74 \%$ of 99 analyzable patients, and $76 \%$ of patients received $>52.5 \mathrm{~Gy}$. The incidence of grade 3/4 late adverse effects was $33.8 \%$, and the incidence of treatment-related deaths was $8 \%$ (early 5, late 3). At 2 years, progression-free survival and OS were $15.8 \%$ and $25.9 \%$, respectively, with $71 \%$ of deaths recognized as cancer-related. Comparing the outcome results from RTOG 9610 and RTOG 9911, the OS rate seems superior in the latter trial $(p=.0444)$.

The studies using reirradiation in patients with unresectable tumors are listed in Table 2. ${ }^{1,23,25-51}$ The review of the reported results shows that at 2 years, one quarter to one third of the patients will be free of locoregional tumor; OS rates in the $10 \%$ to $30 \%$ range can be expected at 2 years of follow-up, although long-term survivors are rare. Late toxicities of grade $3 / 4$ severity may occur in up to $40 \%$ of reirradiated patients, and nearly $10 \%$ of patients will have treatment-related deaths. Obviously, the outcomes differ considerably across these studies and depend primarily on the selection criteria for re-treatment and intensity of the applied therapies. Moreover, there are still questions regarding the most effective reirradiation regimen (split-course vs continuous-course; oncedaily fractionation vs hyperfractionation) and on the added value of concurrent chemotherapy that remain unanswered. To date, no randomized comparison of reirradiation treatment schemes has been conducted, and the wide diversity in patient populations and in tumorrelated and treatment-related parameters across the reported studies prevents any meaningful conclusions.

There are several reasons why the treatment results in the reirradiation series dealing with unresectable disease are inferior when compared to the adjuvant (postoperative) reirradiation series. First, patients referred for salvage surgery have, by definition, operable, lower-volume tumors, compared with those referred for reirradiation, implying, per se, a higher probability for cure in such cases. Furthermore, in surgical candidates, the processes of tissue scarring, initiated during the previous course of RT, are expected to be less prominent and, consequently, involved tissues are likely less hypoxic. After salvage surgery, tumor burden is considerably reduced, and less compromised vasculature and better oxygenation in the treated area make residual tumor cells more sensitive to subsequent RT and better exposed to systemic drugs than is probably the case in patients not amenable for salvage surgery. Last, only patients with good performance status are suitable for general anesthesia and a major surgical procedure, which is a prerequisite for a successful completion of the planned therapy and subsequent rehabilitation.

\section{How to irradiate}

Experiences with re-treatment of patients with head and neck cancer gained during the last decades provide a solid ground for refinement of the existing reirradiation strategies. Moreover, given the enormous progress in RT technology and targeted drug development, several exciting novel paradigms bring new optimism to these patients with traditionally poor prognosis.

Reirradiation volumes. The main challenge in a reirradiation setting is the extent of the clinical target volume (CTV), expanding around the recurrent primary tumor or regional lymph nodes, and whether to electively irradiate the neighboring noninvolved nodal area(s). In this respect, several observations should be taken into account. First, after performing contrast-enhanced CT of the neck in the post-RT setting, the negative predictive value for regional metastases is $>94 \% .{ }^{52}$ Second, differences in the pattern of metastases (the incidence and/or geographic distribution of metastases) can be expected after previous RT. Changes in nodal size and the caliber of lymphatic vessels have been observed in the irradiated lymphatic tissue, with marked hyalinization and fibrotic changes found in lymph nodes irradiated with doses of $>40 \mathrm{~Gy} .{ }^{53-55}$ Also, lymphoscintigraphy performed as part of the sentinel node procedure in early oral cancer showed an unexpected lymph drainage pattern in $67 \%$ of the patients with a previously treated neck. ${ }^{56}$ Third, high rates of local failures and systemic metastases reported in patients after local and/or regional salvage treatment markedly reduce the potential therapeutic gain that would be expected from elective $\mathrm{RT}^{57}$ Locoregional recurrence and second primary tumors have been identified as highrisk factors for the development of distant metastases. ${ }^{58}$

Considering only recent reirradiation series with a more consistent utilization of contemporary imaging for target determination and computer-assisted three-dimensional (3D) RT planning, ${ }^{57,59-69}$ it seems that, at the site of recurrence, the reirradiation CTV should include the GTV/tumor bed with no or only a narrow margin $(\leq 0.5$ $\mathrm{cm}$ ) of the normal-appearing surrounding tissue. The margin is intended to cover potential microscopic tumor extensions and/or compensate for geographic uncertainties originating from an imperfect visualization of the tumor/ normal-tissue border, as well as differences in the appearance of the GTV resulting from the implementation of various imaging modalities. 70

The need for any "safety" margin around GTV was questioned by Popovtzer et al. ${ }^{57}$ They expanded GTV by $0.5 \mathrm{~cm}$ to form a planning target volume (PTV): 45 to 47 (96\%) of local failures in their series occurred within the high-dose reirradiation volume. Moreover, using SBRT, Wang et al ${ }^{71}$ used no margin at all around the visually delineated GTV $(\mathrm{GTV}=\mathrm{CTV}=\mathrm{PTV})$. In the non-positron emission tomography-CT (non-PET-CT) planning group, 25 of 44 patients $(57 \%)$ had a local recurrence: 11 of 25 recurrences (36\%) occurred "in field" $(\geq 20 \%$ of the recurrent tumor inside the GTV), whereas 14 of 25 recurrences (64\%) were declared as marginal $(<20 \%$ inside the GTV, but with the 


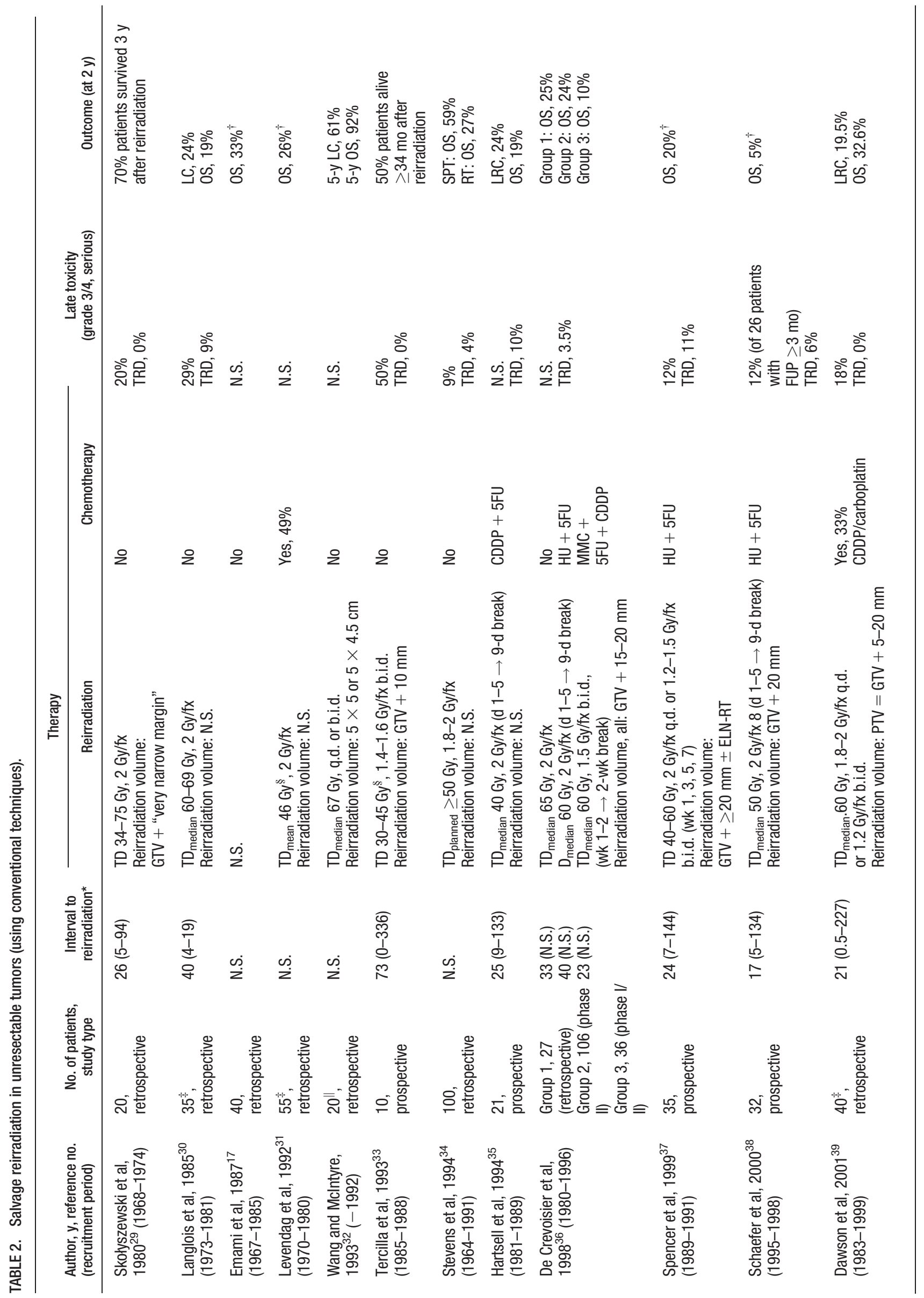


ב

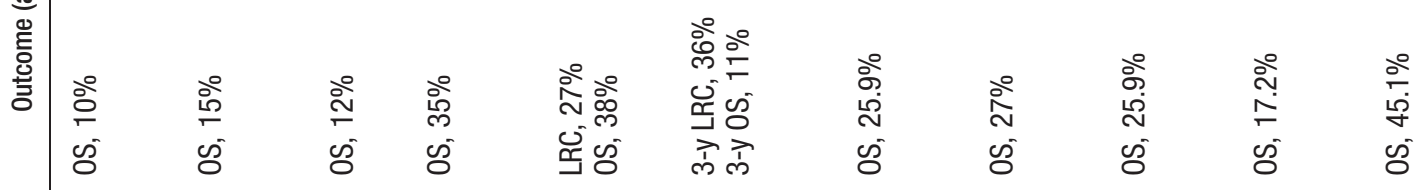

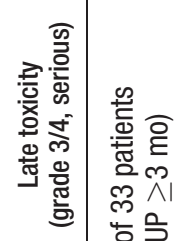

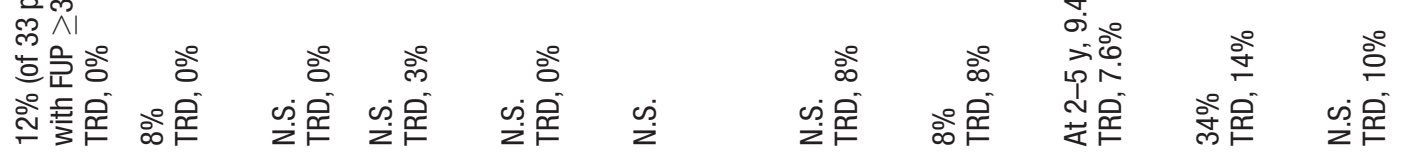

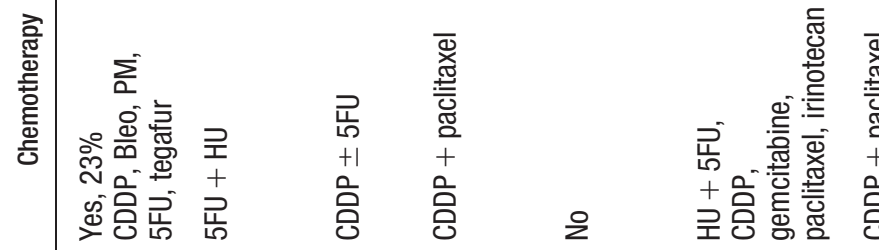

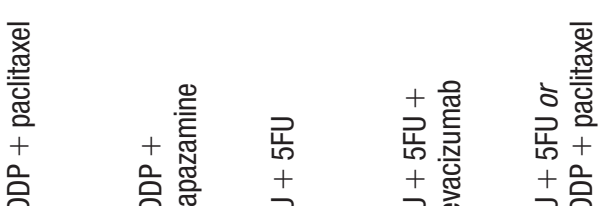

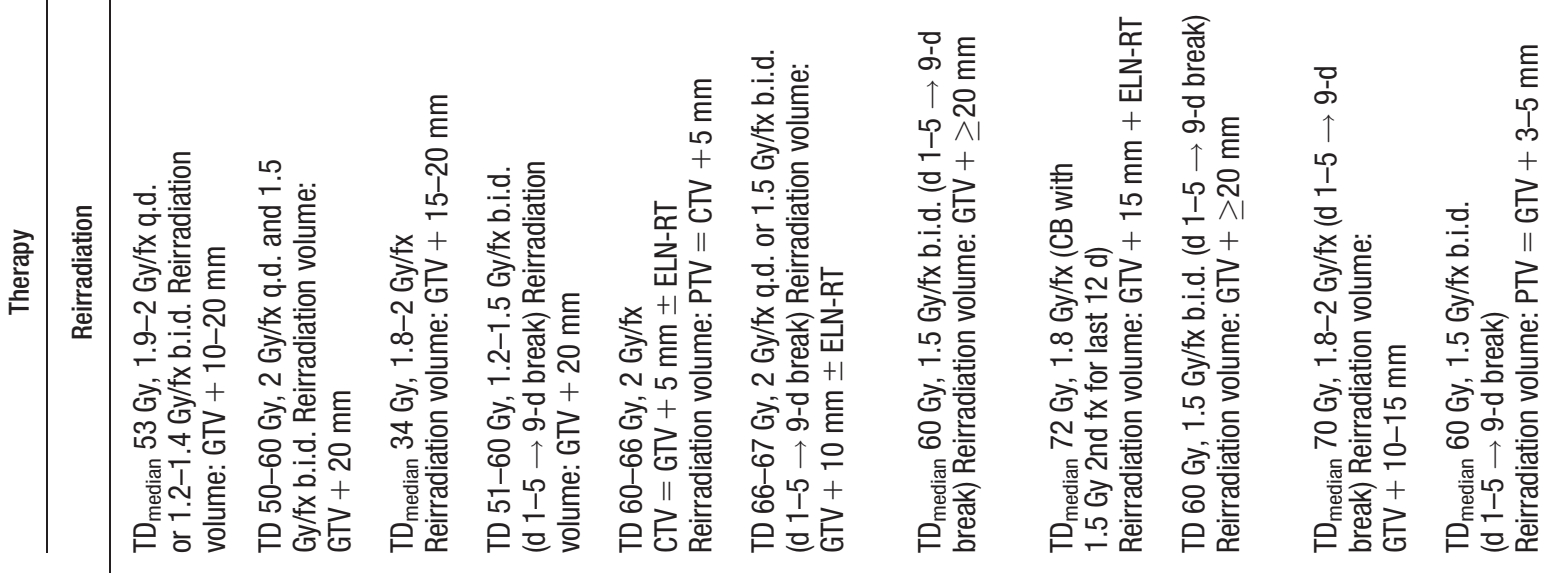

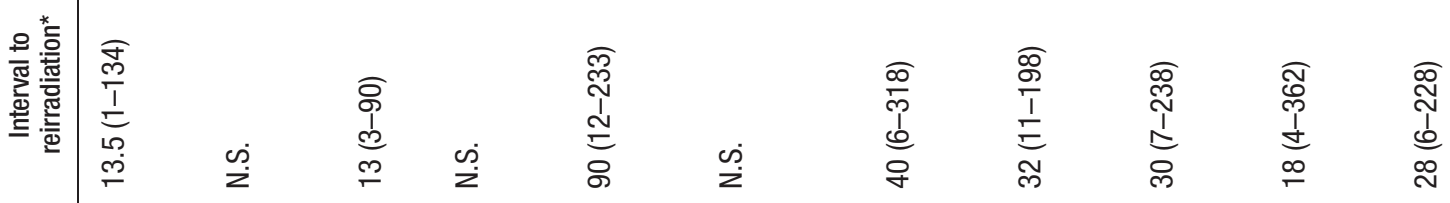

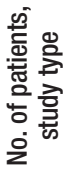

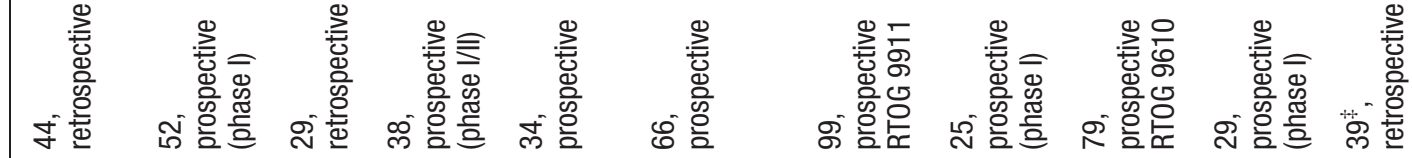
突 न

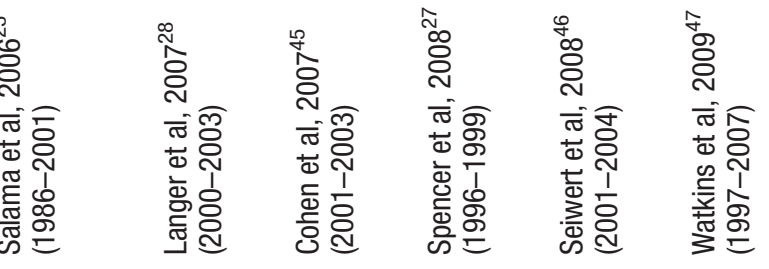




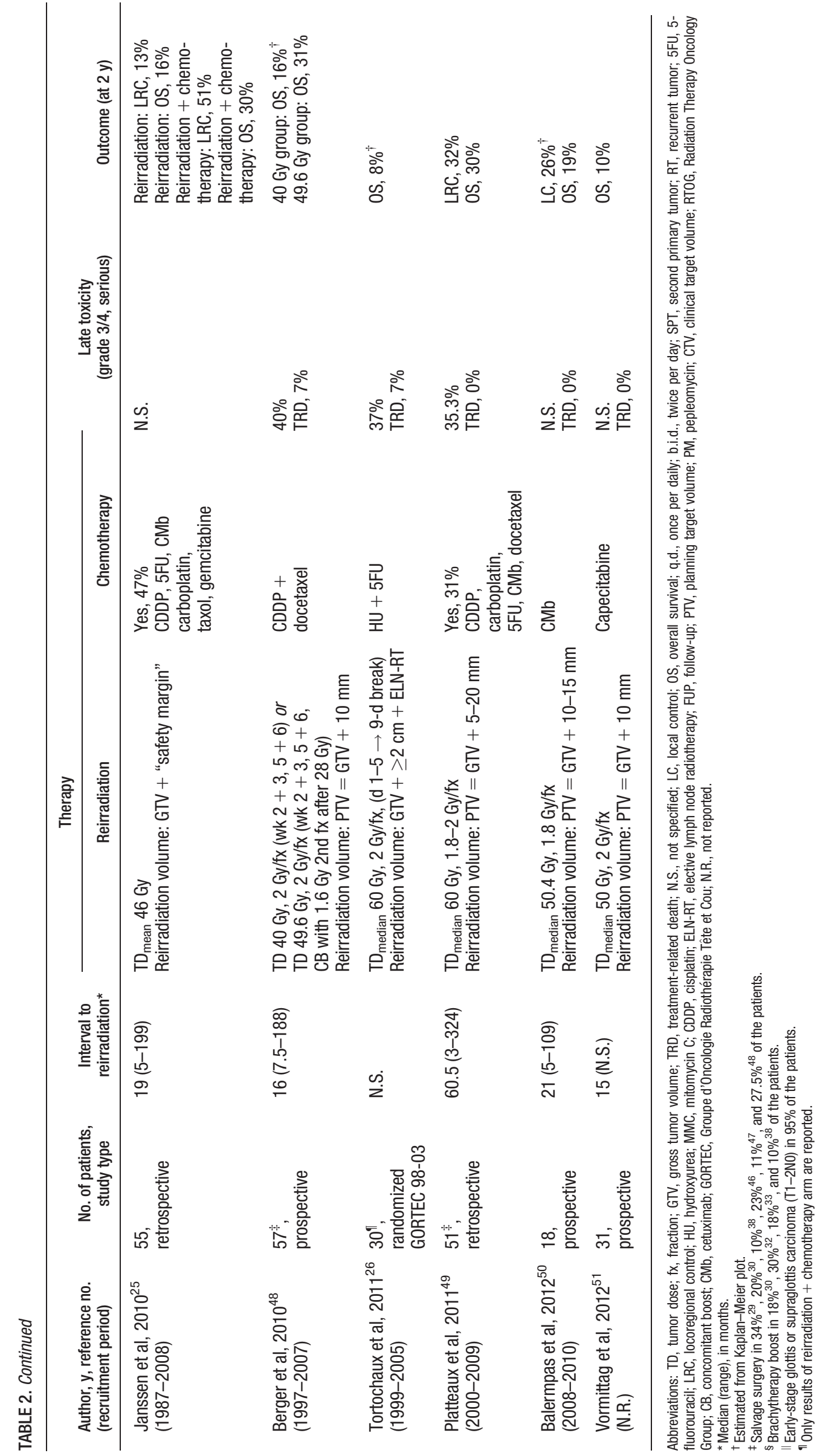


closest edge within $1 \mathrm{~cm}$ of the GTV). In the PET-CT planning group (45 patients with 16 local recurrences), there were only 6 of 16 marginal failures (38\%). After retrospectively adding margins of 1 to $5 \mathrm{~mm}$ to the GTVs, a median coverage of recurrence volumes, as measured by the GTVrecurrence volume overlap, increased from $11.7 \%$ (GTV $+0 \mathrm{~mm}$ ) to $48.2 \%$ (GTV $+5 \mathrm{~mm}$ ) in non-PET-CT patients and from $45 \%$ to $93.6 \%$ in PET-CT-planned patients. The authors concluded that margins of up to $5 \mathrm{~mm}$ around the GTV may effectively reduce failures but could possibly increase toxicity. The similarity of GTV size and disparity of outcome between the 2 types of planning suggests that PET-CT planning may alter GTV location rather than volume. With PET-CT planning, near-miss failures can be effectively reduced with a smaller increase in GTV size.

With regard to elective reirradiation of the regional lymphatics, 3 clinical scenarios must be considered. First, in patients with isolated local recurrence and clinically and radiographically N0 necks who were originally treated with elective RT to cN0 necks, the risk of occult neck disease is generally low, usually not justifying elective treatment to the neck. Dagan et $\mathrm{al}^{72}$ reported on 57 such patients who underwent salvage surgery of recurrent primary with or without neck dissection. Occult metastases were found in 4 of 46 dissected specimens $(9 \%$; in 4 of 40 patients; $10 \%$ ), and only 1 of the observed patients had neck recurrence. None of these patients had an isolated neck recurrence. By adding neck dissection, no improvement in LRC, cause-specific survival, or OS was found, whereas the likelihood of adverse events was increased. Summarizing the results from 6 recent literature series dealing with patients surgically salvaged for isolated locally recurrent $\mathrm{HNSCC}^{72-77}$ after (chemo)-RT for initially staged $\mathrm{cNO} \mathrm{HNSCC}$, the rate of pathologically involved nodes was $10 \%$ among a total of 274 patents. A comparably low rate of occult nodal metastasis (8\%) was found in 13 patients diagnosed with a second node-negative primary HNSCC who had already received elective neck RT. ${ }^{78}$ In patients with recurrent supraglottic/hypopharyngeal tumors or rT3-4 tumors, however, the risk of occult metastases in the neck lymphatics seems higher, and these patients may benefit from elective (re)treatment of the neck. ${ }^{73,75,79}$

The second scenario includes patients with an isolated local recurrence who were initially treated for nodepositive disease. In this group, elective treatment of regional lymphatics might be indicated. Solares et $\mathrm{al}^{80}$ reported on 69 patients who underwent 96 selective neck dissections and found histologically positive nodes in $25 \%$ of the patients (23\% of the operated hemi-necks). There were no recurrences in salvaged necks when the primary site was controlled, and the pattern of lymphatic spread was found unaffected by previous RT. In the recent series of Amit et al, ${ }^{79}$ elective dissection revealed occult nodal metastases in 4 of 8 patients $(50 \%)$ and 2 of 26 patients $(8 \%)$ who received RT to the neck at initial treatment for $\mathrm{N}+$ and $\mathrm{N} 0$ disease, respectively. In the group previously irradiated for early-stage (T1-2N0) glottic (12 cases) or supraglottic ( 2 cases) primaries but having no elective neck RT, the rate of occult metastases was $14 \%$ (2 of 17 neck specimens; 12\%), whereas the risk of metastases in the contralateral neck was $0 \%(0$ of
9). Recently, Lee et $\mathrm{al}^{81}$ also found a significant advantage for elective neck dissection during salvage surgery in node-positive patients at initial treatment and recurrent cases that developed within 1 year.

The third scenario consisted of patients with isolated regional recurrence. In line with the surgical experiences and differences related to the use of previous neck RT, the CTV in adjuvant reirradiation should include only the involved nodal levels, whereas for unresectable neck tumor, the CTV should encompass the GTV with a margin, adapted to a geographic distribution of high-dose areas created during previous RT to the neck. ${ }^{82}$

\section{Radiotherapy regimen and normal tissue tolerance to reirradia-}

tion. No objective comparison of various reirradiation regimens has been conducted to date. Experiences collected from irradiation of RT-naive patients with HNSCC suggest hyperfractionated regimens with proven capacity for sparing late-reacting normal tissues in the vicinity of the target to be the most effective. ${ }^{83}$ A rather high fraction dose of $1.5 \mathrm{~Gy}$ delivered twice daily in "1-weekon/1-week-off" or similar fashion was tested by the RTOG and in some others studies. ${ }^{21,23,27,28,36,37,43,47}$ No apparent advantage of these prolonged regimens was seen with regard to treatment efficacy or toxicity compared to similar split-course regimens using 1 daily fraction $^{16,20,23,35-38,46,48}$ or continuous course regimens with either hyperfractionation or conventional fractionation of 1.8 to 2 Gy/day. ${ }^{18,22,29-34,36,39-42,44,45,49-51}$

In the majority of reirradiation studies, the reported profile of acute toxicity remains within the limits of those observed during the initial course of RT or it was less intensive, probably because of smaller target volumes used in reirradiated patients. Specifically, hematologic toxicity depends primarily upon the intensity of systemic component of the re-treatment regimen and is usually not affected by prior therapy. Conversely, this is not the case with late radiation-induced morbidity. In a cohort of 103 patients treated between 1998 and 2008, late toxicities of grade $\geq 3$ occurred in $47.5 \%{ }^{84}$ and, in another study using different RT techniques, they were found more frequent in patients treated with 3D-conformal RT than in patients treated with IMRT $(44 \%$ vs $7 \% ; p<.05) .{ }^{69}$ Even though there is usually a window, albeit narrow, to burden preirradiated late-reacting tissues with an additional dose, including the spinal cord as the most critical among these structures, the need for reducing the extra dose as much as possible is obvious.

Ang et $\mathrm{al}^{85}$ demonstrated a significant capacity of the spinal cord to recover from occult radiation injury. Modeling clinical data from reirradiation experiments performed on monkeys previously irradiated to $44 \mathrm{~Gy}$ in a $2.2-$ Gy per daily fraction, recovery estimates of $76 \%$, $85 \%$, and $101 \%$ of the initial dose, after 1,2 , and 3 years, respectively, at the 5\% incidence level for myoparesis, were done. Recently, Kirkpatrick et al $^{86}$ summarized the existing knowledge on this issue and concluded that a partial repair of subclinical damage in the cord produced by conventionally fractionated RT of the full cord crosssection becomes evident about 6 months post-RT (ie, reirradiation at $2 \mathrm{~Gy} /$ day: increase in cord tolerance of at 
least 25\%) and increases over the next 2 years. For partial cord RT using SBRT, a maximum cord dose of $13 \mathrm{~Gy} / 1$ fx or $20 \mathrm{~Gy} / 3 \mathrm{fx}$ seems associated with a $<1 \%$ risk of injury. In routine practice, Sulman et $\mathrm{al}^{63}$ assumed, using this background data, a $50 \%$ dose tolerance recovery of central nervous system structures, if the posttreatment interval is $\geq 12$ months. Also, Nieder et al $^{87}$ suggested that the spinal cord might tolerate significant reirradiation doses (eg, 25 Gy in 30 fractions after previous exposure of 45 Gy in 35 fractions). Several studies reported on the methods for an accurate assessment of the delivered dose on different spinal cord sections and planning techniques to spare doses to the spinal cord and brainstem, which could be of considerable importance in a reirradiation setting. ${ }^{88,89}$

A pooled analysis of published data on carotid blowout, another dreaded complication of reirradiation, determined a rate of $2.6 \%$ at a median of 7.5 months postreirradiation; $76 \%$ of events were fatal. ${ }^{90}$ No impact of previous salvage surgery or administration of concurrent chemotherapy was established. A lower rate of carotid blowout was found among patients treated in a continuous course with conventional fractionation or hyperfractionation compared to accelerated hyperfractionation regimens $(1.3 \%$ vs $4.5 \% ; p=.002)$, although a heterogeneous patient population and treatment parameters preclude definitive conclusions about the impact of fractionation.

The estimated incidences of other late radiation-induced toxicities are less systematic and accurate. Swallowing impairment seems to be the most common toxicity, reported in up to $50 \%$ or more of treated patients. $^{27,48,67,91}$ However, dysphagia is still less frequent than expected, particularly when the baseline functional status resulting from the first RT course is taken into account. ${ }^{27,44,48}$ Because of the same reason, sparing of parotid glands during reirradiation planning is of minor importance. The rates of mandibular osteoradionecrosis reported in larger reirradiation series using predominantly conventional RT techniques were up to $10 \%,{ }^{36,84,91}$ and did not correlate with any of the RT/reirradiation parameters. ${ }^{36}$ Because of more precise planning and targeting, reirradiation with modern RT techniques (IMRT, SBRT) resulted in a significantly reduced rate of mandibular necrosis, ranging from $0 \%$ to $7 \%$ (median $0 \%$ ). ${ }^{57,59-69,92-}$ 101 Obviously, options offered with reconstructive surgery as a necrosis-rescuing procedure or preventative swallowing exercise programs cannot outweigh the importance of precise RT planning and dose delivery. ${ }^{102}$ Besides the mandibular bone, other tissues, like the laryngeal cartilages and brain, are also sensitive to radiation. Consequently, the localization of the tumor influences the type of radiation-induced toxicity.

Tumor regrowth is thought to result from repopulation of radioresistant clonogens that survive the first course of RT, which are likely to be more difficult to control with a repeated course of RT. From this perspective, high RT doses seem mandatory, although, in a reirradiation scenario, one must consider the tradeoff for the efficacy and morbidity of high-dose RT. A dose-effect relationship was established in several reirradiation studies. ${ }^{17,23,25,29,30,33-36,38,40,47-49,51,59,60,63,84,91-93}$ In different studies, the cut-point dose suggesting an improved outcome is usually set at around 60 Gy. By increasing the dose above this level, extreme caution is warranted, as the aim to cure does not always justify excessive morbidity and deterioration in the patient's QOL. Thus, when deciding on the reirradiation dose, one must take into account the volume of the tissue to be reirradiated (GTV with margin, eventually neighboring lymph node stations), the level of precision of the RT technique used, and the latency period from the first RT course. There was a strong relationship established between treatment-related morbidity and reirradiation volume, ${ }^{36,39,40,57,64,84,93}$ RT technique (see below) and RT-reirradiation time interval. ${ }^{27-30,34,37,38,43,64,84,85,91,94}$

New irradiation techniques. Capability to deliver nonuniform photon fluency from any given position to the treatment beam allows a more precise isodose shaping (according to the 3D shape of the target), whereas the increased implementation of modern imaging and stereotactic principle in RT practice resulted in improved disease targeting. Both modulation of beam intensity and image guidance were widely adopted in RT practice because of their potential to significantly change the toxicity profile and/or treatment efficacy compared with conventional RT techniques. ${ }^{102-104}$

Reports on the use of IMRT and SBRT are presented in Tables 3 and 4. ${ }^{57,59-69,92-101}$ In general, the numbers of patients treated in individual series are low and a wide heterogeneity can be observed with regard to RT details and implementation of salvage surgery and/or systemic therapy across these studies. Compared to conventional techniques, no obvious survival advantage can be observed with IMRT or SBRT. However, improvement in local tumor control can be seen, despite the fact that the treated volumes seem smaller when new RT techniques are used. No conclusions can be drawn with regard to toxicity and treatment-related deaths, presumably because of a less systematic collection of pertinent data in older series.

Lee et al $^{60}$ retrospectively evaluated the efficacy and toxicity data of 105 patients who underwent reirradiation with curative intent between 1996 and 2005 with either conventional RT techniques (31 patients) or IMRT (74 patients). The IMRT approach yielded a significantly better locoregional recurrence-free survival over non-IMRT techniques at 2 years $(52 \%$ vs $20 \% ; p<.001)$ and was also recognized as an independent prognosticator in the multivariate analysis (HR, 0.37). For OS, the advantage of the IMRT technique was only observed by univariate analysis, implying that an improvement in LRC did not transfer to improve the OS. No separate data on toxicity was presented for the 2 treatment groups. For locally recurrent nasopharyngeal carcinoma, 3D-conformal RT (27 patients) and robotic SBRT (24 patients) were compared by Ozyigit et al. ${ }^{105}$ No apparent difference in tumor dose, volume, and time interval between the first RT and reirradiation was found between the groups; in 3Dconformal RT patients, larger margins were used $(\mathrm{PTV}=\mathrm{GTV}+5-10 \mathrm{~mm}$ vs PTV $=\mathrm{GTV})$, and the cumulative nasopharyngeal dose was lower (128.2 Gy vs 132.6 $\mathrm{Gy} ; p=.1)$. At 2 years, local control rates were similar in the 2 groups ( $80 \%$ vs $82 \%$ ), with no significant difference in cancer-specific survival (47\% vs $64 \%)$. However, 


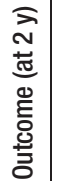

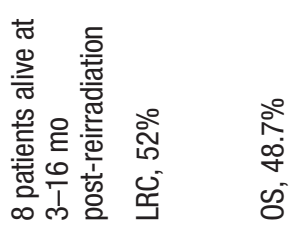

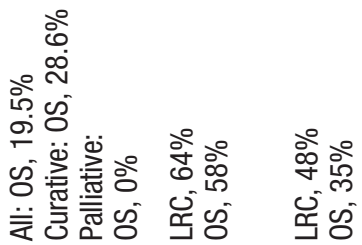

ลิํำ ถิำ

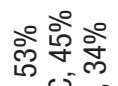

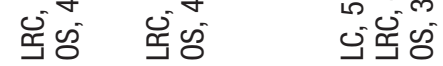

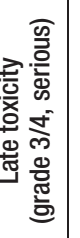

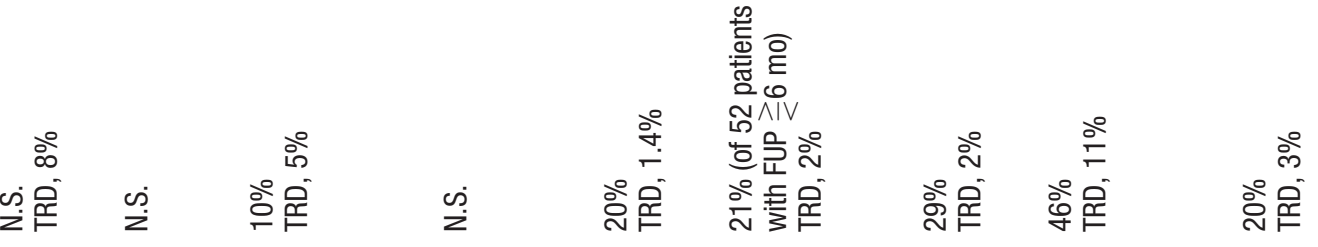

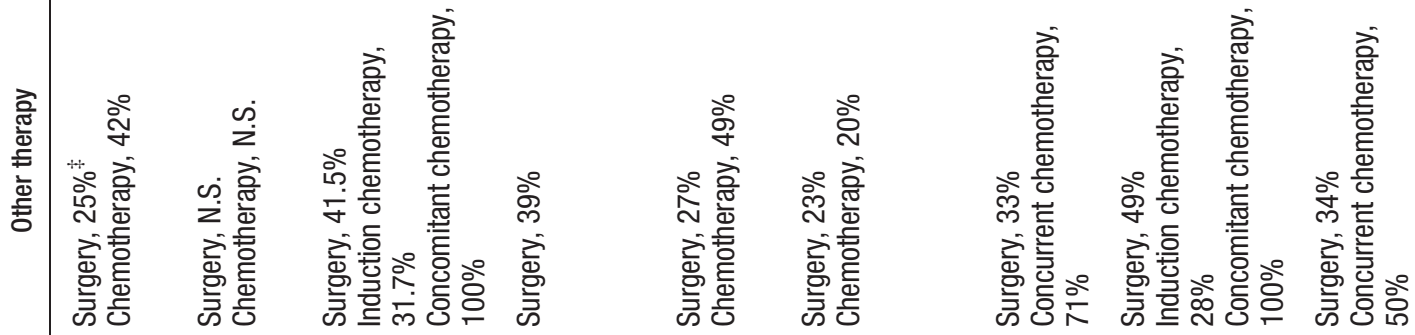

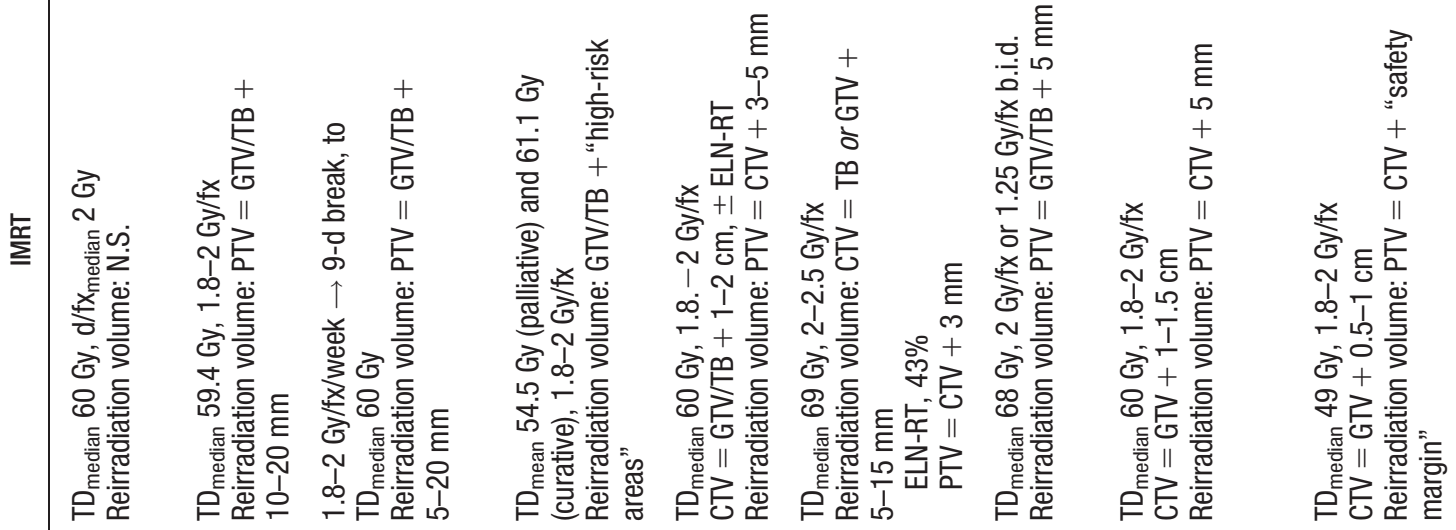

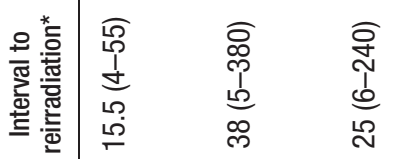

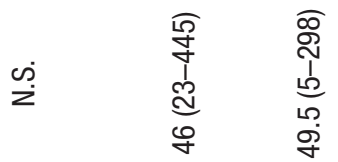

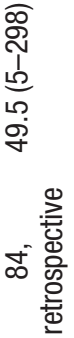

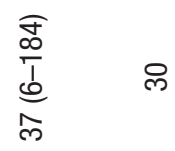

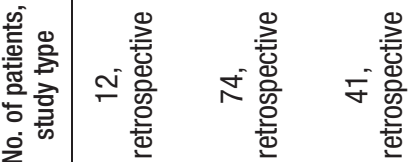

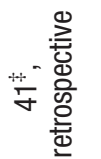

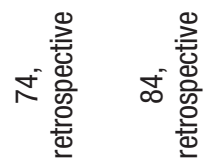

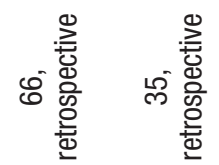

承

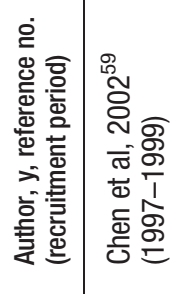

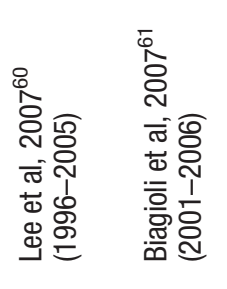

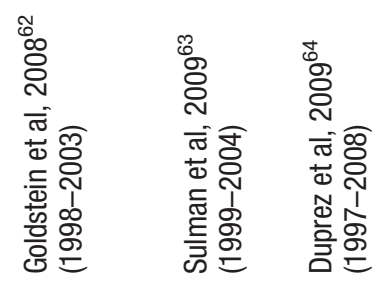

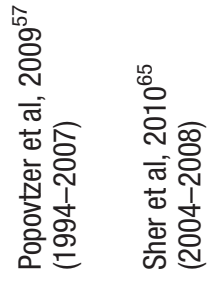

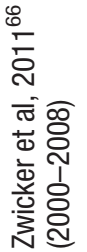




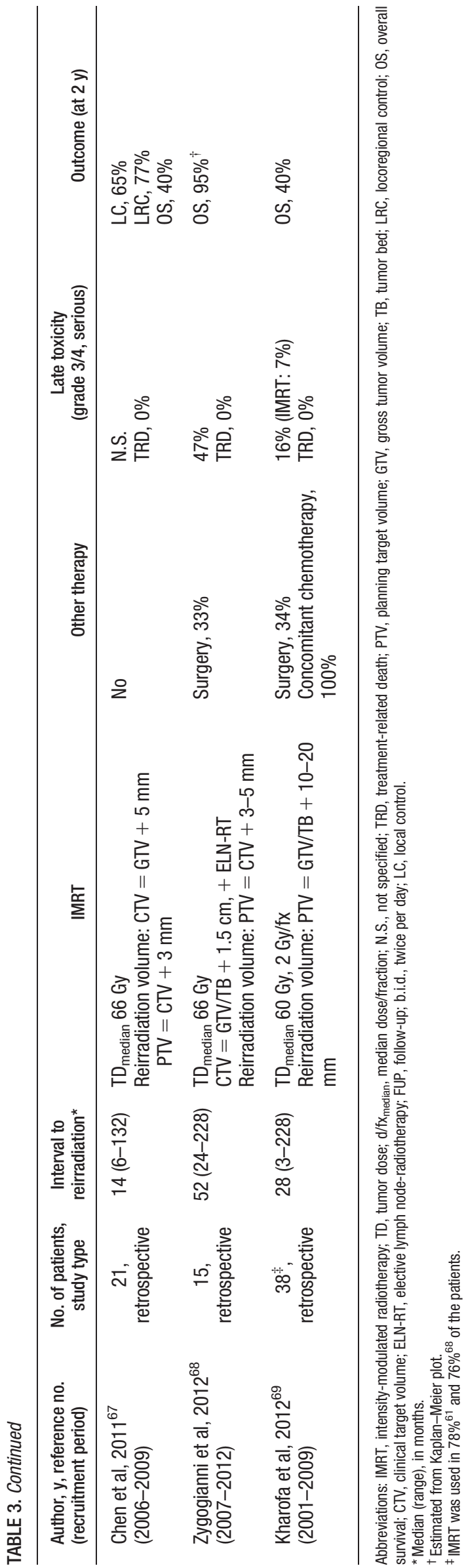

serious late complications were more frequent with 3Dconformal RT ( $48 \%$ vs $21 \%$; $p=.04)$, but the incidence of fatal complications was comparable (14.8\% vs $12.5 \%)$, and no correlation was found between the cumulative nasopharyngeal dose and the rate of serious late adverse events.

Combinations with systemic agents. Whether the addition of systemic agents to RT improves the effectiveness of reirradiation is not known. There have been no head-tohead comparisons of reirradiation versus combined modality therapy, and the results of selective studies implementing reirradiation alone compete favorably with those of chemotherapy reirradiation series. For example, in a definitive and postoperative setting, excellent LRC and OS were reported using only a well-defined RT protocol without any chemotherapy. ${ }^{2,44}$ The explanation may lay in the refinement of RT procedures that can counterbalance the addition of systemic drugs, although a reduced effectiveness of systemic agents in a reirradiation setting could not be excluded. On the other hand, presented results are based on small and mainly retrospective studies: taking into account the fact that in large randomized studies of upfront RT vs chemotherapy-RT the survival benefit is about $6 \%$, there is simply no chance to detect a potential benefit of concomitant chemotherapy in these retrospective series. ${ }^{2}$ One may hypothesize that the benefit of concurrent chemotherapy, and also cetuximab, in a reirradiation setting is likely to be similar to their respective benefits in large randomized studies of upfront therapy.

Considering the report from the MACH-NC, concomitant administration of systemic drugs with reirradiation would be expected to increase treatment intensity and result in an improved outcome compared to reirradiation alone. $^{2}$ Few studies reported on an improved outcome with an increase in the intensity of the chemotherapy component of re-treatment regimens. ${ }^{28,47,48}$ In this respect, an intriguing finding was reported by Choe et al, ${ }^{91}$ who analyzed the treatment results and survival of 166 previously irradiated patients with nonmetastatic HNSCC from 9 consecutive phase I and II protocols on concurrent chemotherapy and reirradiation. Half of the cohort $(48.8 \%)$ underwent salvage surgery or debulking before reirradiation, with a median dose of 66 Gy. After dividing the patients with respect to previous use of chemotherapy, significantly better OS (at 2 years: $28.4 \%$ vs $10.8 \% ; p=.0043)$ and DFS $(p=.0008)$ rates were recorded in chemotherapy naive patients. A similar observation was reported by Nagar et al. ${ }^{42}$ Patients who had initial RT did significantly better (DFS, $p=.01$; OS, $p=.008)$ compared with those who were initially treated by concomitant chemo-RT. One can hypothesize that previous intensive chemotherapy-RT regimens resulted in a more pronounced proliferation of fibrous tissue in the treated area, and when ineffective, it is likely that recurrence consisted of surviving highly RT-resistant tumor clonogens. In poorly vascularized, fibrotic regions, drug delivery is compromised and RT-resistant hypoxic areas are more extensive. Consequently, subsequent treatment may not be as effective as expected.

Several different chemotherapy regimens have been utilized concurrently with reirradiation, most frequently 


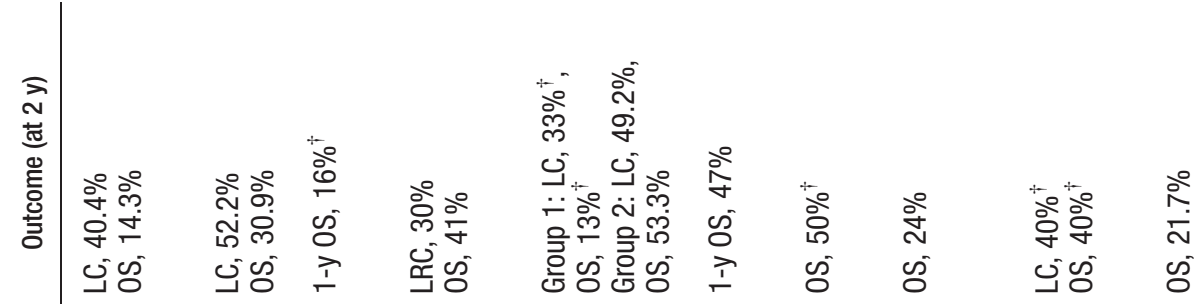

竞

ले

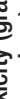

离

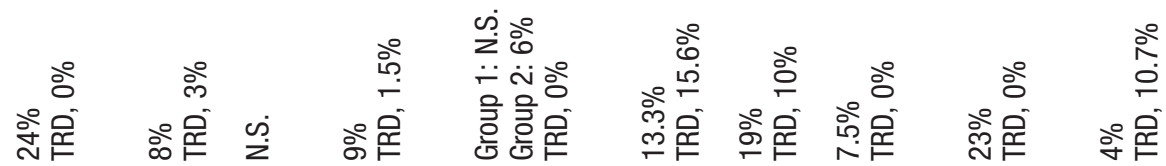

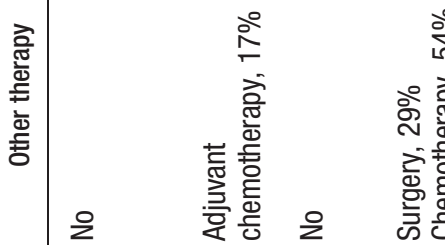

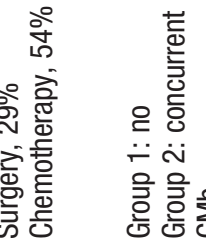

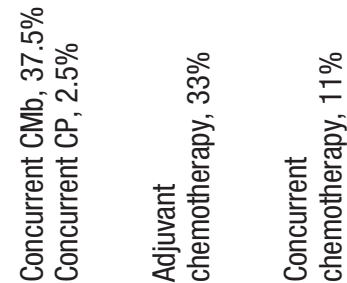

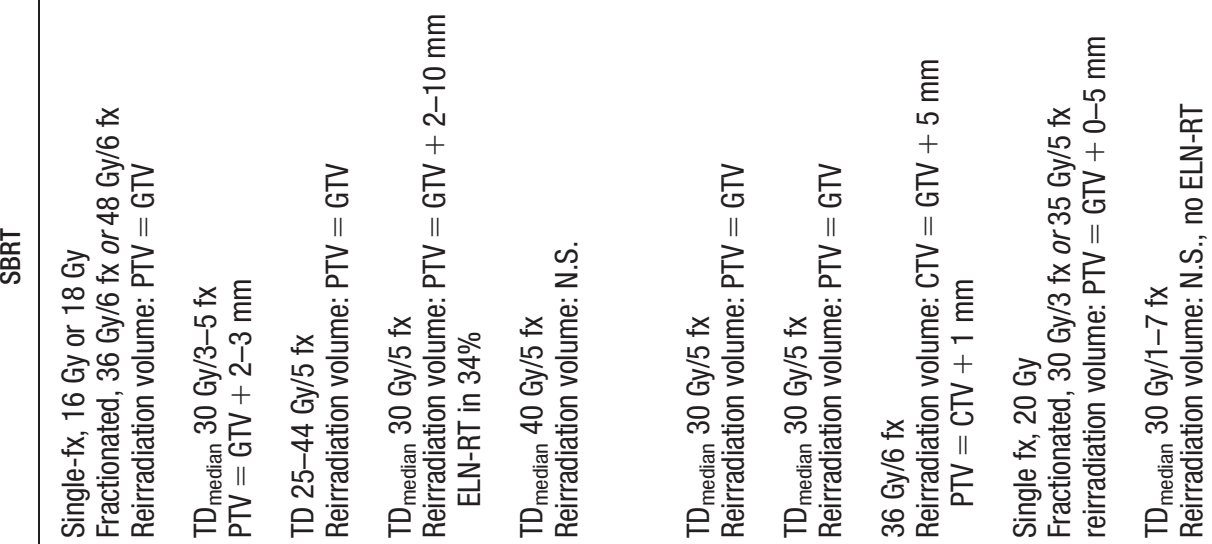
-

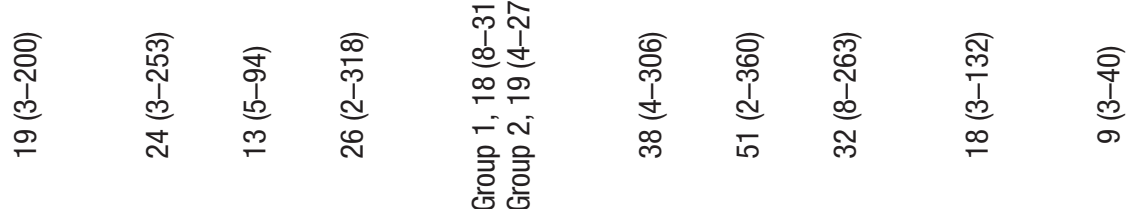


platinum-based and those consisting of 5FU-hydroxyurea platform invented and extensively tested at the University of Chicago. ${ }^{23,91}$ However, no comparison of their efficacy is possible, mainly because of the retrospective nature of the reports and heterogeneity of different study parameters. Furthermore, the toxicity reporting seems inconsistent in many of these studies, not allowing any reliable assessment of the tolerance and safety of the tested regimens. Several combinations of reirradiation and other/new drugs were tested in phase I settings: bendamustine, an alkylating agent, ${ }^{106}$ the hypoxia-targeting agent tirapazamine, ${ }^{45}$ the proteasome inhibitor bortezomib, ${ }^{107}$ the epidermal growth factor receptor inhibitor erlotinib, alone or in combination with cyclooxygenase-2 inhibitor celecoxib, ${ }^{108,109}$ antivascular endothelial growth factor agent bevacizumab, ${ }^{46}$ and the paclitaxel-cisplatin combination. ${ }^{110}$ No apparent advantage in the efficacy or toxicity profile was observed in these studies compared to more frequently used chemotherapy and reirradiation combinations.

More information is available on reirradiation with cetuximab, which proved effective in combination with RT, with acceptable toxicity in therapy-naive patients. ${ }^{111}$ Moreover, the toxicity profile differed significantly from that associated with the platinum-based and other chemotherapy regimens usually used in patients with HNSCC. In addition to small retrospective and pilot-study reports, ${ }^{25,49,50,66,99}$ there are 2 larger series on the use of cetuximab and reirradiation. ${ }^{97,112}$ Heron et $\mathrm{al}^{97}$ used standard-dose cetuximab concurrently with SBRT $(5 \times 8$ Gy delivered every other day) in 35 patients with recurrent HNSCC, who were matched with 35 patients retreated with SBRT alone. Patients were matched by age, sex, performance status, year of treatment, and prior therapy, including radiation dose, interval to recurrence, as well as recurrent disease characteristics (site, size, and presence of systemic metastases). At 2 years, the local control rates were $33.6 \%$ for the SBRT-alone group and $49.2 \%$ for the cetuximab-SBRT group (HR for local progression, $0.37 ; p=.009)$, respectively, with 2-year OS rates of $21.1 \%$ and $53.3 \%$ (HR for death, $0.59 ; p=.031$ ). A survival advantage was also observed in patients who received cetuximab during the first course of RT and were re-treated with cetuximab-SBRT combination. On multivariate analysis, performance status, nasopharynx primary, SBRT dose, and cetuximab predicted for improved survival. There were no grade $\geq 4$ acute toxicities, no difference in the acute or late toxicity profile between the 2 groups, and the incidence of grade 3 late adverse effects were $3 \%$ and $6 \%$, respectively.

In another report, Vargo et $\mathrm{al}^{112}$ compared the patientreported QOL after SBRT with (51 patients) or without (57 patients) concurrent cetuximab, using the University of Washington Quality-of-Life Revised Questionnaire. SBRT consisted of 40 to $50 \mathrm{~Gy}$ in 5 fractions, and cetuximab was administered in standard doses; $24 \%$ of patients had salivary gland/paranasal recurrences, mostly of nonsquamous histology. Overall and health-related patient-reported QOL and select domains commonly affected by reirradiation (ie, swallowing, speech, and saliva) progressively showed significant improvements to baseline. The addition of cetuximab to SBRT had no influence on the observed improvements in QOL. However, the baseline overall QOL was a significant predictor of OS, with patients denoting the overall QOL as "poor" or "very poor" (corresponding to an assigned value of $\leq 20$ ) showing statistically inferior OS at 1 year (23\%) compared to patients reporting "fair" (value $>20$ ) baseline QOL (1 year, 48\%; $p=.014$ ).

Outside of a clinical trial, cetuximab should be administered as a single agent during reirradiation. Given the individual radiosensitizing effects of cetuximab and cytotoxic chemotherapies, as well as the potency of cetuximab administered with platinum-based chemotherapy in incurable settings, combining the 2 approaches (cetuximab plus cisplatin) with RT initially seemed intuitive and promising. However, the RTOG 0522 phase III trial in previously untreated patients failed to demonstrate improved outcomes of the cisplatin/cetuximab combination over cisplatin alone, suggesting no further enhancement effect above that reached with cisplatin, but yet leading to more toxicity. ${ }^{113}$

\section{When to irradiate}

Appropriate patient selection is crucial when deciding on reirradiation to avoid unnecessary morbidity in those with a short life expectancy. Several risk factors for OS and adverse events were identified in different studies, which were recently extensively elaborated by Yamazaki et al. ${ }^{114}$ However, low patient numbers, selection bias, inconsistency in reporting on treatment details and toxicity, and inadequate follow-up make the findings from these studies questionable.

In 2011, Choe et $\mathrm{al}^{91}$ reviewed their experience with 166 patients with recurrent and second primary HNSCC, representing the largest reirradiation cohort analyzed so far, with a median follow-up of 53 months. For OS, salvage surgery (before reirradiation, $\mathrm{HR}=0.52$; $p=.0006)$, previous chemo-RT (HR, 1.83; $p=.0043)$, RT dose $\geq 60$ Gy (HR, 0.35; $p<.0001$ ), and the time interval from previous RT of $\geq 36$ months (HR, 0.64; $p=.0259)$ were significant independent prognostic variables. After stratifying the patients according to the number of prognostic factors present, the OS differed significantly among the risk groups $(p<.0001)$ with the rate of $30 \%$ at 5 years (estimated from the Kaplan-Meier plot) in the most favorable risk group ( $0-1$ adverse prognostic factors). All those with 3 to 4 unfavorable risk factors had died before that time. Patient-related factors had no influence on the survival in this cohort, most probably because $80 \%$ of the patients were Eastern Cooperative Oncology Group performance status 0 to 1 .

A detailed analysis of the potential prognostic factors for survival, including comorbidity and preexisting organ dysfunction, was conducted by Tanvetyanon et $\mathrm{al}^{84}$ on a group of 103 patients with HNSCC treated with reirradiation during 1998 to 2008. Comorbidity was assessed by Charlson index and Adult Comorbidity Evaluation-27 (ACE-27) grading, whereas organ dysfunction was defined as feeding tube dependency, functioning tracheostomy, or soft-tissue defect. On multivariate analysis, in addition to disease-related variables (interval since last RT, rT-classification, tumor bulk after salvage surgery) and treatment-related variables (reirradiation dose), organ dysfunction and comorbidity (measured either by Charlson index or ACE-27 comorbidity grading) also 


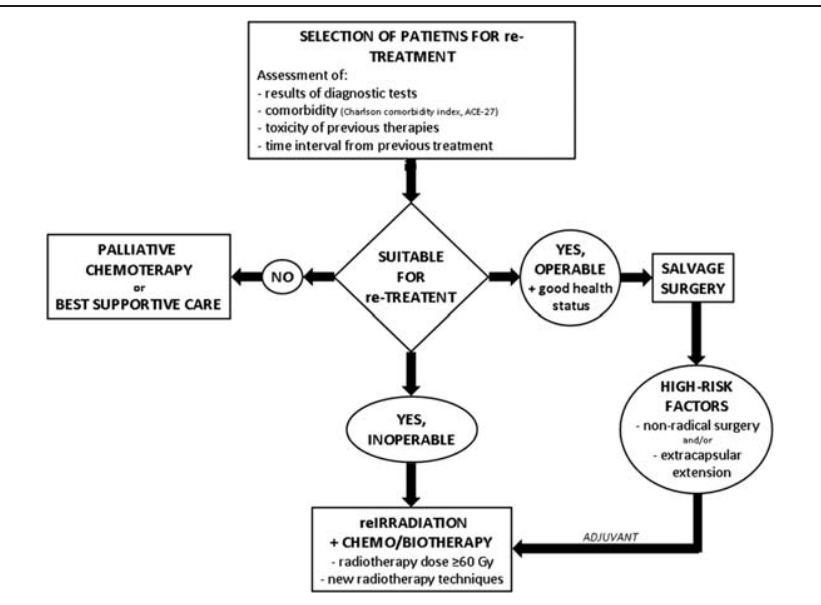

FIGURE 1. Reirradiation: management algorithm.

exhibited the ability to independently predict survival. If both comorbidity and organ dysfunction were present, no long-term survivors were observed (median survival 5.5 months vs 59.6 months in patients with neither of the 2 predictors). Using significant prognostic factors, a nomogram was created to predict the probability of death within 24 months after reirradiation, taking into account their contribution to the accuracy of prediction. A good agreement between the predicted and the observed outcomes was found with this nomogram (concordance index 0.75 ), showing a negligible chance of survival at 2 years after reirradiation for most patients with organ dysfunction and comorbidity and those who did not have an isolated nodal recurrence. The nomogram has already been successfully tested by entering data of 28 patients reported by Shikama et al. ${ }^{101}$

\section{CONCLUSIONS}

The following principles and recommendations based on prospective and retrospective data analyses should be considered when planning a treatment strategy for patients with locoregional recurrence or new primary cancer in a previously irradiated area (Figure 1). First, proper selection of patients for reirradiation is crucial. Only those with no or insignificant comorbidity and toxicity of previous RT should be considered candidates for re-treatment. If possible, the functional status of the patient should be assessed by using standardized measures (ie, the Charlson comorbidity index or ACE-27 grading). Other predictors that should be taken into account are presence of isolated neck recurrence, tumor bulk, and the time interval from previous RT, preferably in the context of the published nomogram. ${ }^{84}$ Second, salvage surgery offers the best chance for cure and should be performed whenever possible. Patients at high risk for local recurrence after surgery (eg, positive margins, extracapsular tumor spread) should be advised that adjuvant reirradiation is expected to increase LRC at the expense of higher toxicity and without survival advantage as compared to no postoperative reirradiation. ${ }^{15}$ Thrid, new RT techniques are recommended for patients undergoing reirradiation. Although there was no significant effect of IMRT or SBRT on the OS, improved dose distribution with high isodose conformity and a steep dose gradient at the target's margin limits injury to the neighboring tissues and may improve RT outcomes in terms of local control and toxicity. Fourth, significant repair of subclinical damage produced by previous RT can occur in the spinal cord. For reirradiation of the full cord cross-section at 2 Gy per day, at least $25 \%$ increase in cord tolerance 6 months after prior conventionally fractionated RT can be considered ${ }^{86}$ or $50 \%$ dose tolerance recovery if the posttreatment interval is $\geq 12$ months. ${ }^{63}$ Fifth, a radiation dose in the range of $\geq 60 \mathrm{~Gy}$ is recommended, delivered by using conventional fractionation (1.8-2 Gy/fx), hyperfractionation, or hypofractionation (in case of SBRT). With adequate imaging support, preferably implementing PET-CT for target volume determination, GTV with a margin of up to $5 \mathrm{~mm}$ to create CTV should be irradiated, with no intention to electively treat the adjacent regions in a majority of patients. Sixth, the benefit of concurrent chemotherapy (or cetuximab) and reirradiation is expected to be similar to their respective benefits observed in large randomized studies of upfront therapy. Seventh, for patients with poor prognostic factors who are not candidates for surgery or aggressive reirradiation with or without concomitant systemic therapy, palliative systemic therapy and best supportive care remain appropriate options. Eighth, when available, all patients should be considered for participation in clinical trials. At the moment, the key knowledge gaps that should be addressed in future multi-institutional reirradiation clinical trials or comparative effectiveness research seem to be the refinement of selection criteria for aggressive reirradiation and comparison of different RT techniques (IMRT vs SBRT) and concomitant systemic therapies.

\section{REFERENCES}

1. Scala LM, Hu K, Urken ML, et al. Intraoperative high-dose-rate radiotherapy in the management of locoregionally recurrent head and neck cancer. Head Neck 2013;35:485-492.

2. Blanchard P, Baujat B, Holostenco V, et al. Meta-analysis of chemotherapy in head and neck cancer (MACH-NC): a comprehensive analysis by tumour site. Radiother Oncol 2011;100:33-40.

3. Wong LY, Wei WI, Lam LK, Yuen AP. Salvage of recurrent head and neck squamous cell carcinoma after primary curative surgery. Head Neck 2003;25:953-959.

4. Taussky D, Dulguerov P, Allal AS. Salvage surgery after radical accelerated radiotherapy with concomitant boost technique for head and neck carcinomas. Head Neck 2005;27:182-186.

5. Bachar GY, Goh C, Goldstein DP, O'Sullivan B, Irish JC. Longterm outcome analysis after surgical salvage for recurrent tonsil carcinoma following radical radiotherapy. Eur Arch Otorhinolaryngol 2010;267:295-301.

6. Nichols AC, Kneuertz PJ, Deschler DG, et al. Surgical salvage of the oropharynx after failure of organ-sparing therapy. Head Neck 2011;33:516524.

7. Slaughter DP, Southwick HW, Smejkal W. Field cancerization in oral stratified squamous epithelium; clinical implications of multicentric origin. Cancer 1953;6:963-968.

8. Wang Z, Sturgis EM, Zhang F, et al. Genetic variants of p27 and p21 as predictors for risk of second primary malignancy in patients with index squamous cell carcinoma of head and neck. Mol Cancer 2012;11:17.

9. Cooper JS, Pajak TF, Rubin P, et al. Second malignancies in patients who have head and neck cancer: incidence, effect on survival and implications based on the RTOG experience. Int J Radiat Oncol Biol Phys 1989;17: 449-456.

10. Erkal HS, Mendenhall WM, Amdur RJ, Villaret DB, Stringer SP. Synchronous and metachronous squamous cell carcinomas of the head and neck mucosal sites. J Clin Oncol 2001;19:1358-1362.

11. Goodwin WJ Jr. Salvage surgery for patients with recurrent squamous cell carcinoma of the upper aerodigestive tract: when do the ends justify the means? Laryngoscope 2000;110(Suppl 93):1-18.

12. Kim AJ, Suh JD, Sercarz JA, et al. Salvage surgery with free flap reconstruction: factors affecting outcome after treatment of recurrent head and neck squamous carcinoma. Laryngoscope 2007;117:1019-1023. 
13. Vermorken JB, Mesia R, Rivera F, et al. Platinum-based chemotherapy plus cetuximab in head and neck cancer. N Engl J Med 2008;359:11161127.

14. Argiris A, Li Y, Forastiere A. Prognostic factors and long-term survivorship in patients with recurrent or metastatic carcinoma of the head and neck. Cancer 2004;101:2222-2229.

15. Paleri V, Kelly CG. Reirradiation with concurrent chemotherapy in recurrent head and neck cancer: a decision analysis model based on a systematic review. Clin Otolaryngol 2008;33:331-337.

16. Janot F, de Raucourt D, Benhamou E, et al. Randomized trial of postoperative reirradiation combined with chemotherapy after salvage surgery compared with salvage surgery alone in head and neck carcinoma. J Clin Oncol 2008;26:5518-5523.

17. Emami B, Bignardi M, Spector GJ, Devineni VR, Hederman MA. Reirradiation of recurrent head and neck cancers. Laryngoscope 1987;97:8588 .

18. Benchalal M, Bachaud JM, François P, et al. [Hyperfractionated reirradiation after salvage surgery in cervico-facial carcinoma. Result of a pilot study in 14 patients]. [Article in French] Cancer Radiother 1997;1:68-73.

19. Nag S, Schuller DE, Martinez-Monge R, Rodriguez-Villalba S, Grecula J, Bauer C. Intraoperative electron beam radiotherapy for previously irradiated advanced head and neck malignancies. Int J Radiat Oncol Biol Phys 1998:42:1085-1089.

20. De Crevoisier R, Domenge C, Wibault P, et al. Full dose reirradiation combined with chemotherapy after salvage surgery in head and neck carcinoma. Cancer 2001;91:2071-2076.

21. Machtay M, Rosenthal DI, Chalian AA, et al. Pilot study of postoperative reirradiation, chemotherapy, and amifostine after surgical salvage for recurrent head-and-neck cancer. Int J Radiat Oncol Biol Phys 2004;59: $72-77$.

22. Kasperts N, Slotman BJ, Leemans CR, de Bree R, Doornaert P, Langendijk JA. Results of postoperative reirradiation for recurrent or second primary head and neck carcinoma. Cancer 2006;106:1536-1547.

23. Salama JK, Vokes EE, Chmura SJ, et al. Long-term outcome of concurrent chemotherapy and reirradiation for recurrent and second primary head-and-neck squamous cell carcinoma. Int J Radiat Oncol Biol Phys 2006;64:382-391.

24. Suh JD, Kim BP, Abemayor E, et al. Reirradiation after salvage surgery and microvascular free flap reconstruction for recurrent head and neck carcinoma. Otolaryngol Head Neck Surg 2008;139:781-786.

25. Janssen S, Baumgartner M, Bremer M, et al. Reirradiation of head and neck cancer-impact of total dose on outcome. Anticancer Res 2010;30: 3781-3786.

26. Tortochaux J, Tao Y, Tournay E, et al. Randomized phase III trial (GORTEC 98-03) comparing reirradiation plus chemotherapy versus methotrexate in patients with recurrent or a second primary head and neck squamous cell carcinoma, treated with palliative intent. Radiother Oncol 2011;100:70-75

27. Spencer SA, Harris J, Wheeler RH, et al. Final report of RTOG 9610, a multi-institutional trial of reirradiation and chemotherapy for unresectable recurrent squamous cell carcinoma of the head and neck. Head Neck 2008;30:281-288.

28. Langer CJ, Harris J, Horwitz EM, et al. Phase II study of low-dose paclitaxel and cisplatin in combination with split-course concomitant twicedaily reirradiation in recurrent squamous cell carcinoma of the head and neck: results of Radiation Therapy Oncology Group Protocol 9911. J Clin Oncol 2007;25:4800-4805.

29. Skołyszewski J, Korzeniowski S, Reinfuss M. The radiation of recurrences of head and neck cancer. Br J Radiol 1980;53:462-465.

30. Langlois D, Eschwege F, Kramar A, Richard JM. Reirradiation of head and neck cancers. Presentation of 35 cases treated at the Gustave Roussy Institute. Radiother Oncol 1985;3:27-33.

31. Levendag PC, Meeuwis CA, Visser AG. Reirradiation of recurrent head and neck cancers: external and/or interstitial radiation therapy. Radiother Oncol 1992;23:6-15

32. Wang CC, McIntyre J. Reirradiation of laryngeal carcinoma-techniques and results. Int J Radiat Oncol Biol Phys 1993;26:783-785.

33. Tercilla OF, Schmidt-Ullrich R, Wazer DE. Reirradiation of head and neck neoplasms using twice-a-day scheduling. Strahlenther Onkol 1993; 169:285-290.

34. Stevens KR Jr, Britsch A, Moss WT. High-dose reirradiation of head and neck cancer with curative intent. Int J Radiat Oncol Biol Phys 1994;29: 687-698.

35. Hartsell WF, Thomas CR Jr, Murthy AK, Taylor SG IV, Haselow RE. Pilot study for the evaluation of simultaneous cisplatin/5-fluorouracil infusion and limited radiation therapy in regionally recurrent head and neck cancer (EST P-C385). Am J Clin Oncol 1994;17:338-343.

36. De Crevoisier R, Bourhis J, Domenge C, et al. Full-dose reirradiation for unresectable head and neck carcinoma: experience at the Gustave-Roussy Institute in a series of 169 patients. J Clin Oncol 1998;16:3556-3562.

37. Spencer SA, Wheeler RH, Peters GE, et al. Concomitant chemotherapy and reirradiation as management for recurrent cancer of the head and neck. Am J Clin Oncol 1999;22:1-5.

38. Schaefer U, Micke O, Schueller P, Willich N. Recurrent head and neck cancer: retreatment of previously irradiated areas with combined chemo- therapy and radiation therapy-results of a prospective study. Radiology 2000;216:371-376.

39. Dawson LA, Myers LL, Bradford CR, et al. Conformal reirradiation of recurrent and new primary head-and-neck cancer. Int J Radiat Oncol Biol Phys 2001;50:377-385.

40. Ohizumi Y, Tamai Y, Imamiya S, Akiba T. Prognostic factors of reirradiation for recurrent head and neck cancer. Am J Clin Oncol 2002;25: $408-413$

41. Spencer S, Wheeler R, Peters G, et al. Phase 1 trial of combined chemotherapy and reirradiation for recurrent unresectable head and neck cancer. Head Neck 2003;25:118-122.

42. Nagar YS, Singh S, Datta NR. Chemo-reirradiation in persistent/recurrent head and neck cancers. Jpn J Clin Oncol 2004;34:61-68.

43. Kramer NM, Horwitz EM, Cheng J, et al. Toxicity and outcome analysis of patients with recurrent head and neck cancer treated with hyperfractionated split-course reirradiation and concurrent cisplatin and paclitaxel chemotherapy from two prospective phase I and II studies. Head Neck 2005;27:406-414.

44. Langendijk JA, Kasperts N, Leemans CR, Doornaert P, Slotman BJ. A phase II study of primary reirradiation in squamous cell carcinoma of head and neck. Radiother Oncol 2006;78:306-312.

45. Cohen EE, Rosine D, Haraf DJ, et al. Phase I trial of tirapazamine, cisplatin, and concurrent accelerated boost reirradiation in patients with recurrent head and neck cancer. Int J Radiat Oncol Biol Phys 2007;67:678-684.

46. Seiwert TY, Haraf DJ, Cohen EE, et al. Phase I study of bevacizumab added to fluorouracil- and hydroxyurea-based concomitant chemoradiotherapy for poor-prognosis head and neck cancer. J Clin Oncol 2008;26: $1732-1741$.

47. Watkins JM, Shirai KS, Wahlquist AE, et al. Toxicity and survival outcomes of hyperfractionated split-course reirradiation and daily concurrent chemotherapy in locoregionally recurrent, previously irradiated head and neck cancers. Head Neck 2009;31:493-502

48. Berger B, Belka C, Weinmann M, Bamberg M, Budach W, Hehr T. Reirradiation with alternating docetaxel-based chemotherapy for recurrent head and neck squamous cell carcinoma: update of a single-center prospective phase II protocol. Strahlenther Onkol 2010;186:255-261.

49. Platteaux N, Dirix P, Vanstraelen B, Nuyts S. Outcome after reirradiation of head and neck cancer patients. Strahlenther Onkol 2011;187:23-31.

50. Balermpas P, Keller C, Hambek M, et al. Reirradiation with cetuximab in locoregional recurrent and inoperable squamous cell carcinoma of the head and neck: feasibility and first efficacy results. Int J Radiat Oncol Biol Phys 2012;83:e377-e383.

51. Vormittag L, Lemaire C, Radonjic D, Kornek G, Selzer E. Reirradiation combined with capecitabine in locally recurrent squamous cell carcinoma of the head and neck. A prospective phase II trial. Strahlenther Onkol 2012; 188:235-242.

52. Hamoir M, Ferlito A, Schmitz S, et al. The role of neck dissection in the setting of chemoradiation therapy for head and neck squamous cell carcinoma with advanced neck disease. Oral Oncol 2012;48:203-210.

53. Kuhn E, Molnár Z, Böhm K. Postirradiation changes on the lymphatics studied by lymphography. Rofo 1979;131:92-96.

54. Jonsson K, Libshitz HI, Osborne BM. Lymphangiographic changes after radiation therapy. AJR Am J Roentgenol 1978;131:803-806.

55. Burge JS. Histological changes in cervical lymph nodes following clinical irradiation. Proc R Soc Med 1975;68:77-79.

56. Flach GB, Broglie MA, van Schie A, et al. Sentinel node biopsy for oral and oropharyngeal squamous cell carcinoma in the previously treated neck. Oral Oncol 2012;48:85-89.

57. Popovtzer A, Gluck I, Chepeha DB, et al. The pattern of failure after reirradiation of recurrent squamous cell head and neck cancer: implications for defining the targets. Int J Radiat Oncol Biol Phys 2009;74:1342-1347.

58. de Bree R, Deurloo EE, Snow GB, Leemans CR. Screening for distant metastases in patients with head and neck cancer. Laryngoscope 2000; 110:397-401.

59. Chen YJ, Kuo JV, Ramsinghani NS, Al-Ghazi MS. Intensity-modulated radiotherapy for previously irradiated, recurrent head-and-neck cancer. Med Dosim 2002;27:171-176.

60. Lee N, Chan K, Bekelman JE, et al. Salvage reirradiation for recurrent head and neck cancer. Int J Radiat Oncol Biol Phys 2007;68:731-740.

61. Biagioli MC, Harvey M, Roman E, et al. Intensity-modulated radiotherapy with concurrent chemotherapy for previously irradiated, recurrent head and neck cancer. Int J Radiat Oncol Biol Phys 2007;69:1067-1073.

62. Goldstein DP, Karnell LH, Yao M, Chamberlin GP, Nguyen TX, Funk GF. Outcomes following reirradiation of patients with head and neck cancer. Head Neck 2008;30:765-770.

63. Sulman EP, Schwartz DL, Le TT, et al. IMRT reirradiation of head and neck cancer-disease control and morbidity outcomes. Int J Radiat Oncol Biol Phys 2009;73:399-409.

64. Duprez F, Madani I, Bonte K, et al. Intensity-modulated radiotherapy for recurrent and second primary head and neck cancer in previously irradiated territory. Radiother Oncol 2009;93:563-569.

65. Sher DJ, Haddad RI, Norris CM Jr, et al. Efficacy and toxicity of reirradiation using intensity-modulated radiotherapy for recurrent or second primary head and neck cancer. Cancer 2010;116:4761-4768. 
66. Zwicker F, Roeder F, Hauswald H, et al. Reirradiation with intensitymodulated radiotherapy in recurrent head and neck cancer. Head Neck 2011;33:1695-1702.

67. Chen AM, Farwell DG, Luu Q, Cheng S, Donald PJ, Purdy JA. Prospective trial of high-dose reirradiation using daily image guidance with intensity-modulated radiotherapy for recurrent and second primary headand-neck cancer. Int J Radiat Oncol Biol Phys 2011;80:669-676.

68. Zygogianni A, Kyrgias G, Kouvaris J, et al. Reirradiation in head and neck cases using IMRT technique: a retrospective study with toxicity and survival report. Head Neck Oncol 2012;4:78.

69. Kharofa J, Choong N, Wang D, et al. Continuous-course reirradiation with concurrent carboplatin and paclitaxel for locally recurrent, nonmetastatic squamous cell carcinoma of the head-and-neck. Int J Radiat Oncol Biol Phys 2012;83:690-695.

70. Daisne JF, Duprez T, Weynand B, et al. Tumor volume in pharyngolaryngeal squamous cell carcinoma: comparison at CT, MR imaging, and FDG PET and validation with surgical specimen. Radiology 2004;233:93-100.

71. Wang K, Heron DE, Clump DA, et al. Target delineation in stereotactic body radiation therapy for recurrent head and neck cancer: a retrospective analysis of the impact of margins and automated PET-CT segmentation. Radiother Oncol 2013;106:90-95.

72. Dagan R, Morris CG, Kirwan JM, et al. Elective neck dissection during salvage surgery for locally recurrent head and neck squamous cell carcinoma after radiotherapy with elective nodal irradiation. Laryngoscope 2010;120:945-952.

73. Wax MK, Touma BJ. Management of the N0 neck during salvage laryngectomy. Laryngoscope 1999;109:4-7.

74. Temam S, Koka V, Mamelle G, et al. Treatment of the NO neck during salvage surgery after radiotherapy of head and neck squamous cell carcinoma. Head Neck 2005;27:653-658.

75. Yao M, Roebuck JC, Holsinger FC, Myers JN. Elective neck dissection during salvage laryngectomy. Am J Otolaryngol 2005;26:388-392.

76. Farrag TY, Lin FR, Cummings CW, et al. Neck management in patients undergoing postradiotherapy salvage laryngeal surgery for recurrent/persistent laryngeal cancer. Laryngoscope 2006;116:1864-1866.

77. Yirmibesoglu E, Fried D, Shores C, et al. Incidence of subclinical nodal disease at the time of salvage surgery for locally recurrent head and neck cancer initially treated with definitive radiation therapy. Am J Clin Oncol 2013;36:475-480.

78. Falchook AD, Dagan R, Morris CG, Mendenhall WM. Elective neck dissection for second primary after previous definitive radiotherapy. Am J Otolaryngol 2012;33:199-204.

79. Amit M, Hilly O, Leider-Trejo L, et al. The role of elective neck dissection in patients undergoing salvage laryngectomy. Head Neck 2013;35: 1392-1396.

80. Solares CA, Fritz MA, Esclamado RM. Oncologic effectiveness of selective neck dissection in the N0 irradiated neck. Head Neck 2005;27:415-420.

81. Lee DJ, Kwon KH, Chung EJ, Park IS, Kim JH, Rho YS. The role of elective neck dissection during salvage surgery in head and neck squamous cell carcinoma. Acta Otolaryngol 2013;133:886-892.

82. Chopra S, Gupta T, Agarwal JP, Budrukkar A, Ghosh-Laskar S, Dinshaw $\mathrm{K}$. Reirradiation in the management of isolated neck recurrences: current status and recommendations. Radiother Oncol 2006;81:1-8.

83. Bourhis J, Overgaard J, Audry H, et al. Hyperfractionated or accelerated radiotherapy in head and neck cancer: a meta-analysis. Lancet 2006;368: 843-854.

84. Tanvetyanon T, Padhya T, McCaffrey J, et al. Prognostic factors for survival after salvage reirradiation of head and neck cancer. J Clin Oncol 2009;27:1983-1991.

85. Ang KK, Jiang GL, Feng Y, Stephens LC, Tucker SL, Price RE. Extent and kinetics of recovery of occult spinal cord injury. Int J Radiat Oncol Biol Phys 2001;50:1013-1020.

86. Kirkpatrick JP, van der Kogel AJ, Schultheiss TE. Radiation dose-volume effects in the spinal cord. Int J Radiat Oncol Biol Phys 2010;76(3 Suppl): S42-S49.

87. Nieder C, Grosu AL, Andratschke NH, Molls M. Update of human spinal cord reirradiation tolerance based on additional data from 38 patients. Int J Radiat Oncol Biol Phys 2006;66:1446-1449.

88. Chen CC, Lee CC, Mah D, et al. Dose sparing of brainstem and spinal cord for reirradiating recurrent head and neck cancer with intensitymodulated radiotherapy. Med Dosim 2011;36:21-27.

89. Stoiber EM, Schwarz M, Debus J, Huber PE, Bendl R, Giske K. Regional cumulative maximum dose to the spinal cord in head-and-neck cancer: consideration for re-treatment. Radiother Oncol 2013;106:96-100.

90. McDonald MW, Moore MG, Johnstone PA. Risk of carotid blowout after reirradiation of the head and neck: a systematic review. Int J Radiat Oncol Biol Phys 2012;82:1083-1089.

91. Choe KS, Haraf DJ, Solanki A, et al. Prior chemoradiotherapy adversely impacts outcomes of recurrent and second primary head and neck cancer treated with concurrent chemotherapy and reirradiation. Cancer 2011; 117:4671-4678.

92. Unger KR, Lominska CE, Deeken JF, et al. Fractionated stereotactic radiosurgery for reirradiation of head-and-neck cancer. Int J Radiat Oncol Biol Phys 2010;77:1411-1419.

93. Cengiz M, Özyiğit G, Yazici G, et al. Salvage reirradiation with stereotactic body radiotherapy for locally recurrent head-and-neck tumors. Int $J$ Radiat Oncol Biol Phys 2011;81:104-109.

94. Siddiqui F, Patel M, Khan M, et al. Stereotactic body radiation therapy for primary, recurrent, and metastatic tumors in the head-and-neck region. Int J Radiat Oncol Biol Phys 2009;74:1047-1053.

95. Roh KW, Jang JS, Kim MS, et al. Fractionated stereotactic radiotherapy as reirradiation for locally recurrent head and neck cancer. Int J Radiat Oncol Biol Phys 2009;74:1348-1355.

96. Heron DE, Ferris RL, Karamouzis M, et al. Stereotactic body radiotherapy for recurrent squamous cell carcinoma of the head and neck: results of a phase I dose-escalation trial.Int JRadiat OncolBiolPhys 2009;75:1493-1500.

97. Heron DE, Rwigema JC, Gibson MK, Burton SA, Quinn AE, Ferris RL. Concurrent cetuximab with stereotactic body radiotherapy for recurrent squamous cell carcinoma of the head and neck: a single institution matched case-control study. Am J Clin Oncol 2011;34:165-172.

98. Kodani N, Yamazaki H, Tsubokura T, et al. Stereotactic body radiation therapy for head and neck tumor: disease control and morbidity outcomes. J Radiat Res 2011;52:24-31.

99. Comet B, Kramar A, Faivre-Pierret, et al. Salvage stereotactic reirradiation with or without cetuximab for locally recurrent head-and-neck cancer: a feasibility study. Int J Radiat Oncol Biol Phys 2012;84:203-209.

100. Iwata H, Tatewaki K, Inoue M, Yokota N, Sato K, Shibamoto Y. Salvage stereotactic reirradiation using the CyberKnife for the local recurrence of nasal or paranasal carcinoma. Radiother Oncol 2012;104:355-360.

101. Shikama N, Kumazaki Y, Tsukamoto N, et al. Validation of nomogrambased prediction of survival probability after salvage reirradiation of head and neck cancer. Jpn J Clin Oncol 2013;43:154-160.

102. Paleri V, Roe JWG, Strojan P, et al. Strategies to reduce long-term postchemoradiation dysphagia in patients with head and neck cancer: an evidence-based review. Head Neck 2013. [Epub ahead of print].

103. Wang ZH, Zhang SZ, Zhang ZY, et al. Protecting the oral mucosa in patients with oral tongue squamous cell carcinoma treated postoperatively with intensity-modulated radiotherapy: a randomized study. Laryngoscope 2012;122:291-298.

104. Nutting CM, Morden JP, Harrington KJ, et al. Parotid-sparing intensity modulated versus conventional radiotherapy in head and neck cancer (PARSPORT): a phase 3 multicentre randomised controlled trial. Lancet Oncol 2011;12:127-136.

105. Ozyigit G, Cengiz M, Yazici G, et al. A retrospective comparison of robotic stereotactic body radiotherapy and three-dimensional conformal radiotherapy for the reirradiation of local recurrent nasopharyngeal carcinoma. Int J Radiat Oncol Biol Phys 2011;81:e263-e268.

106. Bottke D, Bathe K, Wiegel T, Hinkelbein W. Phase I trial of radiochemotherapy with bendamustine in patients with recurrent squamous cell carcinoma of the head and neck. Strahlenther Onkol 2007;183:128-132.

107. Kubicek GJ, Axelrod RS, Machtay M, et al. Phase I trial using the proteasome inhibitor bortezomib and concurrent chemoradiotherapy for headand-neck malignancies. Int J Radiat Oncol Biol Phys 2012;83:1192-1197.

108. Rusthoven KE, Feigenberg SJ, Raben D, et al. Initial results of a phase I dose-escalation trial of concurrent and maintenance erlotinib and reirradiation for recurrent and new primary head-and-neck cancer. Int J Radiat Oncol Biol Phys 2010;78:1020-1025.

109. Kao J, Genden EM, Chen CT, et al. Phase I trial of concurrent erlotinib, celecoxib, and reirradiation for recurrent head and neck cancer. Cancer 2011;117:3173-3181.

110. Langer CJ, Duffy K, Horwitz EM, et al. Phase I trial of concurrent hyperfractionated split course radiotherapy (HFx RT), cisplatin (cDDP), and paclitaxel in patients with recurrent, previously irradiated, or treatmentnaive locally advanced upper aerodigestive malignancy. Cancer Invest 2006;24:164-173.

111. Bonner JA, Harari PM, Giralt J, et al. Radiotherapy plus cetuximab for squamous-cell carcinoma of the head and neck. N Engl J Med 2006;354: 567-578.

112. Vargo JA, Heron DE, Ferris RL, et al. Prospective evaluation of patientreported quality-of-life outcomes following SBRT \pm cetuximab for locally-recurrent, previously-irradiated head and neck cancer. Radiother Oncol 2012;104:91-95.

113. Ang KK, Zhang QE, Rosenthal DI, et al. A randomized phase III trial (RTOG 0522) of concurrent accelerated radiation plus cisplatin with or without cetuximab for stage III-IV head and neck squamous cell carcinoma (HNC). J Clin Oncol 2011;29(Suppl):360s (abstract 5500).

114. Yamazaki H, Kodani N, Ogita M, Sato K, Himei K. Reirradiation of head and neck cancer focusing on hypofractionated stereotactic body radiation therapy. Radiat Oncol 2011;6:98. 